\title{
A relação entre o comportamento do indicador de liquidez corrente das empresas de capital aberto do agronegócio pela variação de índices econômicos no Brasil
}

The relationship between the behavior of the current liquidity indicator of publicly traded agribusiness companies by the variation of economic indexes in Brazil

La relación entre el comportamiento del indicador actual de liquidez de las empresas agroindustriales que cotizan en bolsa por la variación de los índices económicos en Brasil

\section{Oto Tertuliano de Oliveira Santana}

Mestre em Ciências Contábeis pelo Programa de Pós-graduação em Ciências Contábeis da Faculdade de Ciências Contábeis da Universidade Federal de Uberlândia (UFU)

Professor da Faculdade de Tecnologia e Ciências Sociais Aplicadas (FATECS) do Centro Universitário de Brasília (UniCEUB)

Endereço: SEPN 707/907 - Campus UniCEUB, Bloco 7 - Asa Norte

CEP: 70297-400 - Brasília/DF - Brasil

E-mail: oto.santana@ ceub.edu.br

Telefone: (61) 3966-1201

\section{Nilton Cesar Lima}

Doutor em Administração pela Universidade de São Paulo (USP)

Professor da Faculdade de Ciências Contábeis e do Programa de Pós-Graduação em Ciências Contábeis da Universidade Federal de Uberlândia (UFU)

Endereço: Av João Naves de Ávila, 2121. Bloco 1-F, Campus Santa Mônica

CEP 38.400-902 - Uberlândia/MG - Brasil

E-mail: niltoncesar@ufu.br

Telefone: (34) 3239-4176

\section{Marcelo Tavares}

Doutor em Agronomia pela Universidade de São Paulo (USP)

Professor da Faculdade de Matemática e do Programa de Pós-Graduação em Ciências Contábeis da Universidade Federal de Uberlândia (UFU)

Endereço: Av João Naves de Ávila, 2121. Bloco 1-F, Campus Santa Mônica

CEP 38.400-902 - Uberlândia/MG - Brasil

E-mail: mtavares@ufu.br

Telefone: (34) 3239-4176

Artigo recebido em 26/02/2018. Revisado por pares em 27/03/2018. Reformulado em 17/04/2020. Recomendado para publicação em 17/04/2020 por Carlos Eduardo Facin Lavarda (Editor-Chefe). Publicado em 24/04/2020. 


\title{
Resumo
}

Inserido num contexto de aumento da importância do agronegócio na economia do país, concomitante a um período de variações econômicas negativas, o objetivo deste artigo foi analisar as relações entre a flutuação de variáveis relacionadas ao contexto econômico do Brasil, com o comportamento do Indicador de Liquidez Corrente (ILC) de 33 empresas do agronegócio, listadas na Bolsa de Valores B3 S.A. entre 2010 e 2016. Como uma pesquisa quantitativa, utilizou-se para o estudo das relações emergentes dos dados, a técnica estática da Análise de Dados em Painel. E os resultados demonstraram que as relações mais significativas para o ILC, partiram das empresas de atividades de suporte ao setor. No contexto macroeconômico, identificou-se uma relação direta entre o PIB e o ILC, e em nível microeconômico a unanimidade das relações entre o ILC e as variáveis independentes, indicaram que a atividade econômica do setor se relacionou significativamente com a sobra financeira de curto prazo das empresas de capital aberto do agronegócio. Concluiu-se que ao medir a relação do ILC pelo comportamento dos índices macroeconômicas do País, que a variável apresentou relação estatisticamente significante apenas com o PIB pelo fato do incremento operacional que a elevação da riqueza do país gerou nos ativos de curto prazo da empresa. Já na métrica estatística da relação microeconômica, a conclusão foi de que o ILC foi impulsionado pelo saldo positivo da balança comercial do agronegócio no período, e pelo bom desempenho da agricultura. Já que a pecuária, observada dentro da variável do PIB do Agronegócio se relacionou negativamente com o ILC das empresas analisadas, e por isso não cooperou com a situação de curto prazo das empresas analisadas expressas a partir do Indicador de Liquidez Corrente (ILC).

Palavras-chave: Indicador de Liquidez Corrente; Índices Econômicos; Análise de Dados em Painel; Empresas de Capital Aberto do Agronegócio Brasileiro

\begin{abstract}
Inserted in a context of increased importance of agribusiness in the country's economy, concomitant with a period of negative economic variations, the objective of this article was to analyze the relationships between the fluctuation of variables related to the economic context of Brazil, with the behavior of the Liquidity Indicator Current (ILC) of 33 agribusiness companies, listed on the B3 SA Stock Exchange between 2010 and 2016. As a quantitative research, the static technique of Panel Data Analysis was used for the study of emerging data relationships. And the results showed that the most significant relationships for the ILC, came from the companies that support the sector. In the macroeconomic context, a direct relationship between the GDP and the ILC was identified, and at the microeconomic level, the unanimity of the relations between the ILC and the independent variables, indicated that the sector's economic activity was significantly related to the short-term financial surplus. publicly traded agribusiness companies. It was concluded that when measuring the ratio of the ILC by the behavior of the country's macroeconomic indices, that the variable presented a statistically significant relationship only with the GDP due to the operational increase that the increase in the country's wealth generated in the company's short-term assets. Regarding the statistical metric of the microeconomic relationship, the conclusion was that the ILC was driven by the positive balance of agribusiness trade balance in the period, and by the good performance of agriculture. Since livestock, observed within the Agribusiness GDP variable, was negatively related to the ILC of the analyzed companies, and therefore did not cooperate with the short term situation of the analyzed companies expressed from the Current Liquidity Indicator (ILC).
\end{abstract}

Keywords: Current Liquidity Indicator; Economic indices; Panel Data Analysis; Publicly Traded Brazilian Agribusiness Companies

\section{Resumen}

Insertado en un contexto de creciente importancia de los agronegocios en la economía del país, concomitante con un periodo de variaciones económicas negativas, el objetivo de este artículo fue analizar las relaciones entre la fluctuación de variables relacionadas con el contexto económico de Brasil, con el comportamiento del Indicador de Liquidez Actual (ILC) de 33 empresas de agronegocios, que cotizaron en la Bolsa de Valores de B3 SA entre 2010 y 2016. Como una investigación cuantitativa, la técnica estática de Panel Data Analysis se utilizó para el estudio de relaciones de datos emergentes. Y los resultados mostraron que las relaciones más significativas para la ILC provienen de las empresas que apoyan al sector. En el contexto macroeconómico, se identificó una relación directa entre el PIB y la ILC, y a nivel microeconómico, la unanimidad de las relaciones entre la ILC y las variables independientes, indicó que 
A relação entre o comportamento do indicador de liquidez corrente das empresas de capital aberto do agronegócio pela variação de índices econômicos no Brasil

la actividad económica del sector estaba significativamente relacionada con el superávit financiero a corto plazo. empresas de agronegocios que cotizan en bolsa. Se concluyó que al medir la razón de la ILC por el comportamiento de los índices macroeconómicos del país, la variable presentaba una relación estadísticamente significativa solo con el PIB debido al aumento operativo que el aumento de la riqueza del país generó en los activos a corto plazo de la compañía. Con respecto a la métrica estadística de la relación microeconómica, la conclusión fue que la ILC fue impulsada por el saldo positivo de la balanza comercial de agronegocios en el período y por el buen desempeño de la agricultura. Dado que el ganado, observado dentro de la variable PIB de Agronegocios, estaba negativamente relacionado con la ILC de las empresas analizadas y, por lo tanto, no cooperó con la situación a corto plazo de las empresas analizadas expresada en el Indicador de Liquidez Actual (ILC).

Palabras clave: Indicador de liquidez actual; Índices económicos; Análisis de datos del panel; Empresas brasileñas de agronegocios que cotizan en bolsa

\section{Introdução}

O crescimento da interação entre os mercados locais e mundiais tem exposto as empresas de todos os lugares do mundo às flutuações econômicas que influenciam seu desempenho. No Brasil, uma das atividades mais importantes para a economia do país, e que tem impulsionado seu desenvolvimento desde o início do século vinte, está na vocação natural do continente, que é o agronegócio (FURTADO, 1959).

Este tem sido um dos setores mais representativos da dinâmica econômica e produtiva dos últimos anos no país, pois de acordo com os dados da Confederação da Agricultura e Pecuária do Brasil (CNA) (2019), em 2018, por exemplo, somente o PIB do agronegócio chegou à R \$1,44 trilhão, o que representou aproximadamente $20 \%$ do PIB do país. E ainda de acordo com estes dados, o destaque do setor foi atribuído ao ramo agrícola, pois $74 \%$ desse valor vieram dele, e o restante foram frutos das participações da agropecuária no setor.

Contextualizando o agronegócio pela perspectiva da questão trabalhista e pela importância da geração de renda, com base na Pesquisa Nacional por Amostra de Domicílios (PNAD) (2015), o setor absorveu praticamente um terço da força de trabalho do país no período analisado, e dos 90 milhões de trabalhadores brasileiros, 13 milhões $(42,7 \%)$ desenvolviam atividades de agropecuária, 6,43 milhões $(21,1 \%)$ no agrocomércio, 6,4 milhões (21\%) nos agrosserviços e 4,64 milhões (15,2\%) na agroindústria, ou seja, o setor empregou aproximadamente $3 \mathrm{em}$ cada 10 trabalhadores brasileiros.

Este desempenho também se complementou pelo cenário do agronegócio brasileiro no ambiente internacional, pois com base nos dados disponibilizados pelo Ministério da Agricultura, Pecuária e Abastecimento (MAPA) dentro do AGROSTAT - Estatísticas de Comércio Exterior do Agronegócio Brasileiro (2018), constatou-se que a partir do ano de 2008 o agronegócio foi o grande responsável pela manutenção dos constantes superávits da Balança Comercial do país. No período (2010 a 2016) em que esta pesquisa analisou as relações que se desenham neste contexto, o agronegócio sustentou o déficit das demais atividades (indústria, comércio e serviços) da economia em todos os anos. Por exemplo, em $2010 \mathrm{o}$ Superávit do Agronegócio foi de 63 Bilhões de dólares, e já o déficit dos demais setores foi de 42,9 Bilhões de dólares, ou seja, um saldo de 20,1 Bilhões de dólares. Estes valores experimentaram algumas oscilações, mas fecharam com saldos positivos de 4,1, 19,7 e 47,6 Bilhões de dólares em 2014, 2015 e 2016 , respectivamente, demonstrando assim, que em toda a série analisada, o aumento constante a partir de 2010 e o desempenho da economia brasileira relacionada ao comércio internacional, foram lastreados pelos resultados do agronegócio no período (MAPA AGROESTAST, 2018).

Outra importante contribuição do setor à economia do país está relacionada a contribuição para a estabilidade de preços no mercado interno. Segundo dados do IBGE (2019), o Índice de Preços ao Consumidor Amplo Global (IPCA - Global) até outubro de 2019, foi de 2,82 \%. Na métrica deste índice de inflação, um dos estimadores que contribuiu para sua redução foi o de alimentação no domicílio $(2,54 \%)$, indicador que absorve a maior parte da flutuação dos preços de produtos in natura, como carnes, grãos e cereais (IBGE, 2019).

Assim, pesquisar como as variáveis macro e microeconômicas se comportaram e como este comportamento influenciou, impactou e ou se relacionou com o desempenho de setores importantes para o país, constrói cenários capazes de minimizar os efeitos negativos da variação econômica inerente à dinâmica mercadológica (COELHO, 2012). 
Por isso, a relevância desta investigação para o agronegócio brasileiro, se assentou na importância que o setor representa para a economia do país. Onde, de acordo com o Centro de Estudos Avançados em Economia Aplicada (CEPEA) (2017), informou que o Produto Interno Bruto (PIB) do setor (riqueza produzida pelo setor e agregada ao PIB do país), cresceu 2,45\% em 2016, mesmo com uma retração da economia no mesmo período, demonstrando uma resistência do setor às intempéries macroeconômicas, mesmo imerso em um contexto de crise.

E com isso, emerge a motivação de se entender como o contexto econômico do país se relacionou com o comportamento das empresas. Neste sentido, este artigo adotou como métrica do desempenho financeiro, a situação de liquidez de curto prazo das empresas de capital aberto do setor do agronegócio brasileiro.

Pois, sabendo-se que a atividade operacional do empreendimento, demanda um determinado montante de ativos líquidos disponíveis para satisfazer o fluxo de caixa do negócio (MARTINS; DINIZ; MIRANDA, 2014), Preve e Allende (2010), explicaram este montante, como sendo o próprio nível de atividade do negócio, já que a efetividade da administração financeira em gerir recursos de curto prazo (capazes de suprir as demandas operacionais e financeiras de custo, gasto e investimentos) pode ser analisada pela ótica da liquidez corrente das empresas que é sinônimo de sobra ou falta financeira de curto prazo.

Absorvida a importância da liquidez para as empresas, o que justificou sua análise para o agronegócio brasileiro no contexto contemporâneo, foi a importância deste setor para a economia do país no contexto supracitado. E a relevância a partir da lacuna existente deste tipo de estudo no agronegócio segundo Serigati (2013). O autor explicou que diversos estudos se dedicaram a analisar a liquidez dos empreendimentos, mas relacionados somente ao contexto de liquidez das ações no mercado acionário e não aos indicadores econômico-financeiros das empresas (CHANG et al., 2017; CHOWDHURY et al., 2017; KHAN et al., 2017; MISHRA; BURNS, 2017; SINGH, SHARMA, 2016; SWITZER; PICARD, 2016; TRENCA et al., 2015). Assim, na literatura são escassos os estudos que analisaram empiricamente cada um dos indicadores econômico-financeiros das empresas, pela variação dos índices econômicos do país, e quando pesquisas deste tipo aconteceram anteriormente, elas trataram estas relações com um número muito reduzido de variáveis independentes (AGGARWAL, 2003; SOLNIK, 1987; SEONEN; AGGARWAL, 1989; SEONEN; HENNIGAR, 1988; MUKHERJEE, 1995; CHAMBERLAIN et al., 1997; CHIEN; CHENG, 2001; OLIVEIRA, 2006; BERNADELLI; BERNADELLI, 2016, TAKAMATSU; LAMOUNIER, 2007; COELHO, 2012, PANDINI et al., 2017; SILVA et al. 2017).

Com base nestas lacunas, Serigati (2013) afirma que academicamente não é seguro, pela falta de aderência ao contexto geral, generalizar os resultados das pesquisas citadas a outros contextos econômicos, políticos, geográficos e sociais. Assim, foram absorvendo-se então estas limitações, que se adotou utilizar um número maior de índices econômicos como variáveis potencialmente relacionáveis à liquidez corrente das empresas, para que as relevâncias econômicas dos resultados pudessem ser expandidas a outros contextos do agronegócio.

Para isso, adotou-se como ponto central o Indicador de Liquidez Corrente (ILC), por se tratar de um indicador que demonstra de modo geral, a existência de sobra ou de demanda financeira na relação entre ativos e passivos de curto prazo (MARTINS; DINIZ; MIRANDA, 2014). Além do que ressaltou Pandini et al. (2017) sobre a possibilidade de se identificar como os índices econômicos, tais como o PIB (Produto Interno Bruto), a Taxa de Juros, a Taxa de Câmbio e a Inflação, se relacionaram com a situação de curto prazo das empresas pela ótica da Liquidez Corrente.

O desenho deste cenário motivou a busca e compreensão de variáveis capazes de responder a seguinte problemática neste artigo: qual a relação entre a flutuação de índices econômicos do país e o comportamento do indicador de liquidez corrente das empresas de capital aberto do setor do agronegócio brasileiro?

Com base nesta motivação de pesquisa, e amparado na relevância econômica do setor do agronegócio para a economia do país, o resultado da interação entre estes dois grupos de variáveis, instigou a problemática deste estudo e cooperou para uma investigação que teve como objetivo geral, analisar como se deu a relação entre a flutuação de variáveis relacionadas ao contexto econômico do país e do setor (macro, micro e de atividade), com o comportamento do Indicador de Liquidez Corrente das empresas de capital aberto do agronegócio entre 2010 e 2016.

Para isto, foram aglutinados os indicadores de 33 empresas do agronegócio brasileiro, escolhidas e 
justificadas metodologicamente com base nos critérios de auto declaração de participação no setor do agronegócio, e com isso elas foram separadas em três grupos do seguinte modo: as 13 empresas que estão classificadas no Grupo Extra, fazem parte da cadeia do agronegócio em atividades de suporte ao setor, como logística, transporte e fornecimentos de insumos; as 20 empresas classificadas no Grupo Intra, realizam atividades da porteira para dentro, ou seja, são o elo essencial do setor (CEPEA, 2016); e já o Grupo Geral representa a união dos dados das 33 empresas da amostra, evidenciando a partir deste grupo evidências do agronegócio como um todo.

Assim, a partir do proposto no problema de pesquisa, no objetivo geral, nos contextos e nas justificativas apresentadas, esta pesquisa buscou construir conhecimento para se estabelecerem para estes três grupos de empresas de capital aberto do agronegócio, listadas na B3 (antiga BM\&FBovespa), qual a relação de seus indicadores de liquidez corrente (ILC), com a flutuação dos índices de três contextos econômicos (macro, micro e de atividade do setor com o mercado externo) entre 2010 e 2016. Com tudo para atingir-se este objetivo, esta pesquisa foi organizada em cinco partes, a Introdução que foi apresentada até este momento, o Referencial Teórico onde foram explicadas as bases conceituais e empíricas que sustentaram as discussões dos resultados encontrados, a seção de Aspectos Metodológicos onde o estudo e seus métodos foram caracterizados, os Resultados e Discussões do estudo que foram abstraídos depois do emprego das ferramentas estatísticas, e as Considerações Finais acerca de todo o trabalho.

\section{Referencial Teórico}

Apresentam-se nesta seção do estudo, as bases conceituais e empíricas que sustentaram as discussões propostas a partir do problema de pesquisa, e busca-se por meio da literatura científica e empírica, lastrear a operacionalização do objetivo geral. Na primeira parte, levantaram-se um breve panorama do agronegócio brasileiro e sua a relação com os índices econômicos (variáveis independentes) (taxa de câmbio, PIB, taxa de juros e inflação).

E em seguida expõem-se aspectos relevantes da análise das demonstrações contábeis sobre o Indicador de Liquidez Corrente (variável dependente) com base em literatura nacional, evidenciando particularidades sobre seu significado e aplicação, fórmula de cálculo e estudos correlatos.

\subsection{Interveniências do Agronegócio e Índices Econômicos do País}

Relacionado ao desenvolvimento do país, a décadas o agronegócio contribui para que a agricultura de subsistência dê lugar à de precisão, elevando pequenos latifundiários ao status de grandes produtores e comercializadores de commodities que contribuem positivamente para a economia (PEACE COR PUS, 1983).

Como um dos principais produtores mundiais de commodities agrícolas $(B 3,2017)$ o desempenho das empresas do agronegócio brasileiro está atrelado (BARROS, 2017) ao desempenho da economia mundial e nacional. E imerso em um ambiente incerto e competitivo (OSAKI, 2017), o setor alavancou sua importância para a economia do país e conquistou posições de destaque no mercado interno frente aos outros setores da economia, e no mercado mundial como produtor de commodities padrão exportação (café, soja, carne, etanol, cítricos, etc.).

Assim, King et al. (2010), explicaram que esta evolução do setor foi sendo estuda, observada e descrita por economistas que se dedicaram a pesquisas relacionadas ao agronegócio, e que nelas detalharam ao longo do tempo, a atuação dos agentes e do próprio conceito de agronegócio, dentro desta que se tornou uma das mais importantes cadeias de suprimentos, sobretudo em países emergentes como é o atual (2018) caso do Brasil.

Ressalta-se também que a expansão desta atuação, foi explicada por Zylberstajn (1995) quando verificou uma tendência mundial de demanda de produtos de origem industrial, subjugando a local. Corroborando, Batalha (2007) já havia explicado que a interação atual do contexto macroeconômico com os agentes que compõe o setor, foi fruto de mudanças que ocorreram desde o final da Segunda Guerra Mundial. E mostrando o início desta relação, Nunes (2007) esclareceu que a partir da Revolução Verde (1950), iniciou-se um processo de abertura do mercado internacional aos países produtores deste tipo de produto, que teve seu ápice com o fenômeno da globalização (décadas de 80 e 90), quando a agricultura passou a ser constituída por importantes complexos industriais, empresariais, agroindustriais e varejistas, aumentando assim o raio de atuação do setor no país e no mundo.

Mas como Serigati (2013) explicou, ainda é restrito o campo de pesquisa que investiga a relação 
das empresas do setor, balizado pelo comportamento da economia. Corroborado por Almeida e Macedo (2010), que sugerem que ao analisar-se o comportamento do agronegócio, deve-se ser capaz de estabelecer o desempenho da atividade pela visão do mercado, esclarecendo a inserção da empresa agrícola no ambiente de negócios onde atua.

Na B3 (2017), dentro dos setores listados, 20 segmentos mantêm registros de 33 empresas com atuação na cadeia produtiva do agronegócio. Esta atuação está em conformidade com o proposto por CEPEA (2014) conforme a Figura 1.

Figura 1 - Estrutura Básica do Agronegócio

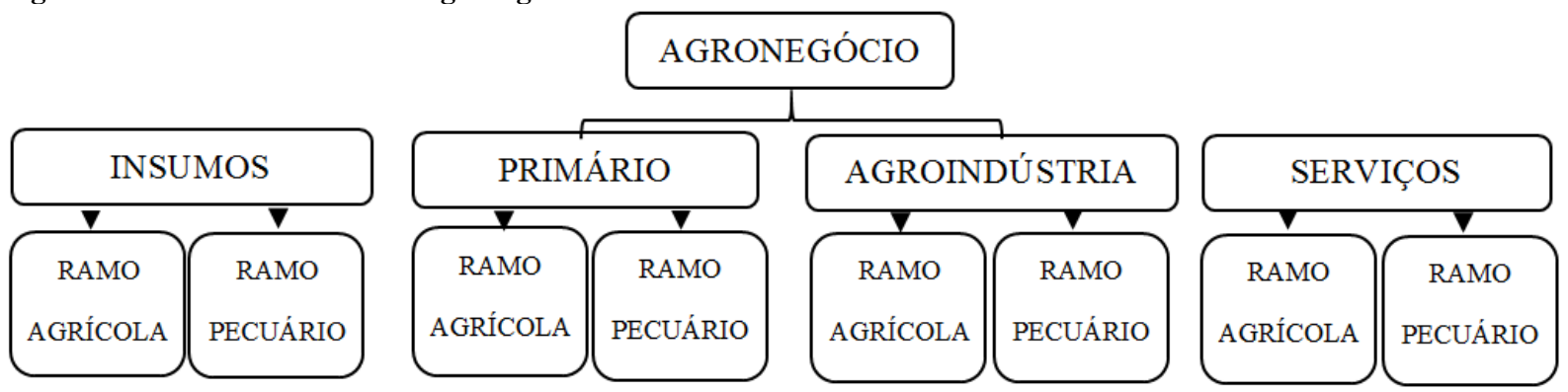

Fonte: adaptado de CEPEA (2016).

É com base no esquema apresentado na Figura 1 que o CEPEA $(2016$, p. 2) explicou que "o agronegócio é entendido como a soma de quatro segmentos: (a) insumos para a agropecuária, (b) produção agropecuária básica ou, como também é chamada, primária ou "dentro da porteira", (c) agroindústria (processamento) e (d) serviços". Complementando o esquema apresentado, Farina e Zylbersztajn (1991, p. 10) ainda definiram esta cadeia produtiva como "[...] um recorte dentro do complexo agroindustrial mais amplo, privilegiando as relações entre agropecuária, indústria de transformação e distribuição em torno de um produto principal".

Assim a aderência de uma determinada empresa à cadeia do agronegócio, não cessa na identificação de sua atuação direta no setor, pois segundo Hall et al. (2011), no agronegócio, observa-se uma heterogeneidade endógena à cadeia, uma vez que empresas agrícolas, pecuárias e agroindustriais dos mais diversos seguimentos, atuam em um mesmo contexto produtivo.

Estabelecida uma noção do atual conceito de agronegócio, e como ele vai além da tradicional propriedade agrícola de subsistência, a exposição da interação do setor com o panorama econômico do país, foi explicada a seguir pela interação do setor com os principais índices econômicos (câmbio, inflação, juros e renda nacional).

Iniciando esta explicação, Nakabashi (2008) evidenciou que no agronegócio, muitas vezes a produção começa a ser viabilizada mesmo que o produtor não saiba o valor que o mercado estará disposto a dispender pelo seu produto, e isto reflete um grande risco de mercado a que o produtor rural se expõe.

Mas, para estimular a produção agrícola e incentivar a permanência deste produtor na atividade (SONAGLIO et al., 2016), o estado intervém na economia colocando sob sua tutela e controle, taxas e políticas que incidem diretamente sobre sua operação. E no sentido desta intervenção, uma das principais ferramentas utilizadas pelos governos, são os instrumentos de política cambial.

Segundo Serigati (2013, p. 16), "em alguns países, a agricultura é o setor que mais contribui para o saldo de transações correntes (o saldo das importações e exportações de bens e serviços)". Neste sentido, o BACEN (2017) delineou que a taxa de câmbio dólar/real sofre interferências do governo, por haver a necessidade de se construir um contexto onde o volume circulante de dólares no mercado interno, não prejudique o saldo da balança comercial do país.

Confirmando a variação cambial como determinante para o entendimento da interação dos agentes macroeconômicos, Krugman e Obstfeld (2012) explicaram que a taxa de câmbio permite que os participantes de um determinado mercado consigam comparar o preço de produtos e insumos em países e contextos econômicos distintos. Assim, o câmbio atua como um denominador comum entre economias de diferentes países, pois uma commoditie produzida no Brasil por sua conversibilidade inerente pode ser cotada, negociada e vendida em diversas partes do mundo.

Pontuando a evolução da taxa de câmbio no país, o DIEESE (2006, p. 5) explicou que a partir "da implantação do Plano Real (julho de 1994) até janeiro de 1999, vigorou no Brasil a taxa de câmbio fixa. Neste regime cambial, [...] o governo impõe à sociedade a taxa de câmbio que, segundo os objetivos de sua 
A relação entre o comportamento do indicador de liquidez corrente das empresas de capital aberto do agronegócio pela variação de índices econômicos no Brasil

política econômica, é a mais adequada para o país”. O departamento complementou que o governo à época, decidindo adotar uma taxa valorizada para o câmbio, estabeleceu a proporção de $\mathrm{R} \$ 1,00$ para cada US\$ 1,00. Os resultados foram a redução das exportações, aumento das importações e o aumento no déficit da balança comercial.

A influência destes movimentos da taxa de câmbio no agronegócio foi complementada por Sonaglio et al. (2016), onde explicou que no momento da desvalorização do real frente ao dólar (período após 1999), os produtores brasileiros optaram por exportar, pois o mercado externo lhe renderia maior lucro nas negociações.

Complementando as proposições teóricas sobre variáveis macroeconômicas e o agronegócio, além da taxa de câmbio, e do volume de importações e exportações do país, identificou-se que o volume de riquezas produzidas (atividade econômica), também afetou tanto o agronegócio, quanto os indicadores das empresas que atuam nele (ADENLE et al., 2017).

Segundo a literatura, uma das maneiras de se medir esta riqueza, é por meio do Produto Interno Bruto (PIB). Na forma básica do conceito, Vasconcellos (2001, p. 207) explicou que o PIB "é a renda devida à produção dentro dos limites territoriais do país". E expandindo-o, Vasconcellos e Garcia (2012, p. 154) propuseram que o PIB, ou a riqueza nacional "é o somatório do que é produzido no período, valorizado a preço de mercado, sem levar em consideração se os fatores de produção são de propriedade de residentes ou não-residentes". Assim, com base nesta conceituação, infere-se que o aumento da renda nacional seja benéfico para todos os setores da economia, pois indicaria que o poder de compra da sociedade tem aumentado.

Contudo, no caso do agronegócio, no curto prazo o movimento é inverso, uma vez que o desenvolvimento do país acaba por alavancar a demanda de produtos beneficiados ou de maior valor agregado. "Ou seja, um aumento de $1 \%$ na renda nacional gera um aumento menor na demanda por produtos agrícolas do que por produtos industriais ou serviços" (SERIGATI, 2013, p. 16), e este é um dos motivos pelos quais, esta pesquisa investigou, como a flutuação econômica do país pode influenciar a situação de curto prazo das empresas.

Assim, ressalta-se também que geração interna de riquezas no país está intimamente ligada (BACEN, 2017) à capacidade de consumo da sociedade, e é neste ponto que outros dois índices econômicos entram em cena, a inflação e a taxa de juros.

Balizadora do consumo das famílias e do nível de investimento das empresas, a taxa de juros é conceituada por Keynes (1985, p. 174) como "a recompensa da renúncia à liquidez, por um período determinado, pois a taxa de juros não é, em si, outra coisa, senão o inverso da relação existente entre uma soma de dinheiro e o que se pode obter desistindo [...], do poder de comando da moeda em troca de uma dívida".

Neste sentido, Pinho e Vasconcellos (1996) explicaram que há no mercado uma crença de que quanto maior for esta taxa, menor será a demanda geral por dinheiro, e continuam explicando que quando isso acontece, consumidores preferem poupar para sacrificar um consumo presente, em troca de um rendimento futuro.

No Brasil esta dinâmica é controlada pelo Banco Central do Brasil (BACEN), em que Barros (2005) explicou que sob a tutela das políticas fiscal e monetária, o BACEN atua estimulando o investimento ou o consumo. $\mathrm{O}$ autor complementa que uma elevação na taxa de juros faz com que as famílias consumam menos bens duráveis, passando a poupar. E neste momento, as instituições financeiras concentram um lastro maior para fornecer crédito aos produtores rurais que captam para investir em sua operação.

O impacto no agronegócio segue neste caminho, para uma taxa de juros elevada, cresce a demanda por bens de consumo não duráveis (in natura e ou de baixo valor agregado). Por isso, Serigati (2013) infere que pela baixa elasticidade-renda da demanda, que as políticas fiscais para estimular (consumo) a economia, exercem pouca influência sobre o comportamento do setor agrícola, até o momento em que esta política provoque aumento no nível geral de preços ocasionando inflação.

Explicando, Serigati (2013) evidencia que o esforço fiscal expansionista por parte do governo, inicialmente confere ganhos de capital ao produtor pelo aumento do preço dos produtos originários da cadeia, mais do que propriamente eleve os índices de atividade e produção do setor. Isto acontece, porque uma vez deflagrado um processo inflacionário, os preços dos produtos de menor valor agregado são mais flexíveis.

Contudo, Keynes (1985, p. 175) já havia alertado que "a taxa de juros não é o "preço" que equilibra 
a demanda de recursos, para investir e a propensão de abster-se do consumo imediato. É o "preço" mediante o qual o desejo de manter a riqueza em forma líquida, se concilia com a quantidade de moeda disponível".

Assim, esclarece-se que este artigo utiliza como taxa de juros, a Taxa SELIC (Sistema Especial de Liquidação e de Custódia), instrumento de controle econômico explicado por Barros (2005), como um sobe e desce da taxa de juros relacionado às decisões do governo. No mercado há um montante considerável de títulos da dívida pública (emitidos para financiar o déficit público), e para atrair compradores para estes títulos, tidos como seguros pelo mercado, o governo remunera este investimento à determinadas taxas. E é "a média das taxas de juros pagas pelos títulos públicos, que recebe o nome de Taxa SELIC" (BARROS, 2005, p. 17).

Barros (2005), ainda explica que através do Comitê de Política Monetária (COPOM) o BACEN pode gerenciar essa taxa elevando ou freando a oferta destes títulos. Quando o governo reduz juros, a economia se aquece, a demanda por crédito aumenta, influenciando positivamente o investimento das empresas e o consumo das famílias. Este cenário progride até o limite em que o poder de compra começa a se deteriorar (inflação), instante em que o governo novamente eleva a SELIC.

Abordando esta relação entre juros e inflação, Barros (2017) explicou que na macroeconomia a taxa de juros atua como balizadora do comportamento da inflação, principalmente por seus efeitos no nível de atividade econômica (PIB e emprego).

Neste sentido, explica-se que tal como o agronegócio, a inflação não é estática, assim Keynes (1985) evidenciou que a verdadeira inflação é na verdade a expressão de uma economia em pleno emprego. Pois neste instante, todas as intervenções para alavancar os investimentos, independentemente da vontade de consumo, impulsionariam o nível geral de preços ao limite.

Para a cadeia do agronegócio, Barros (2017) complementou que deflagrado na economia um comportamento inflacionário positivo, há uma elevação do custo de captação de recursos para os produtores e uma corrosão da capacidade de compra dos consumidores. Isso segundo o autor não é um processo de simples reversão no Brasil, pois tanto a concorrência entre as commodities agropecuárias e minerais no mercado internacional, quanto o câmbio no mercado interno, contribuem para uma inflação de oferta. Assim "as causas dos altos custos do controle da inflação no Brasil estão relacionadas ao significativo grau de indexação da economia, que enfraquece o efeito dos juros e potencializa os efeitos dos cada vez mais frequentes choques de oferta oriundos do comportamento do clima sobre agropecuária" (BARROS, 2017, p. 1).

Por isso, confirmando a pertinência desta dinâmica, Vasconcellos e Garcia (2012, p. 127) conceituaram a inflação "como o aumento contínuo e generalizado no nível geral de preços". E recorrente na economia do país, o contexto inflacionário brasileiro foi resumido a partir do exposto por Carvalho (2014) e organizado conforme o Quadro 1.

Quadro 1 - Breve Histórico da inflação brasileira

\begin{tabular}{|c|c|}
\hline $\begin{array}{l}1964 \text { - PAEG - Plano de Ação } \\
\text { Econômica do Governo. }\end{array}$ & $\begin{array}{l}\text { Cria-se o instituto jurídico da correção monetária, fornecendo aos títulos } \\
\text { públicos atratividade no mercado (embrião da hiperinflação). Institucionaliza-se } \\
\text { a indexação econômica. }\end{array}$ \\
\hline $\begin{array}{l}\text { Década de } 70 \text { e } 80 \text { - Crises econômicas, } \\
\text { choques de demanda. }\end{array}$ & $\begin{array}{l}\text { Acirramento do processo inflacionário e da redução do poder de compra dos } \\
\text { consumidores, somado ao impacto de crises econômicas ao redor do mundo. }\end{array}$ \\
\hline 1994 - Plano Real & $\begin{array}{l}\text { "Desindexação plena a partir da conversão total de todos os contratos para a } \\
\text { nova moeda, proibindo-se a utilização de qualquer mecanismo de indexação para } \\
\text { contratos de prazo inferior a um ano" (CARVALHO, 2014, p. 267). }\end{array}$ \\
\hline $\begin{array}{l}1995 \text { a } 2000 \text { - PEM - Programa de } \\
\text { Estabilidade Econômica. }\end{array}$ & $\begin{array}{l}\text { Nova elevação do nível geral de preços e consequente ação do governo buscando } \\
\text { austeridade fiscal, câmbio flutuante e sistema de metas de inflação. }\end{array}$ \\
\hline $\begin{array}{l}\text { Anos } 2000 \text { em diante - Nova elevação } \\
\text { do nível geral de preços. }\end{array}$ & $\begin{array}{l}\text { Justificado pelos reflexos do processo de desindexação da economia do país com } \\
\text { o Plano Real. Pela Política Monetária expansionista dos países desenvolvidos, } \\
\text { após a crise financeira norte americana em 2007. E pela Política Econômica } \\
\text { expansionista durante os mandatos do presidente Luiz Inácio Lula da Silva. }\end{array}$ \\
\hline
\end{tabular}

Este histórico demonstrou que a atuação do governo na gestão do processo inflacionário é constante no Brasil. Mas Vasconcellos e Garcia (2012, p. 127) justificaram que certo nível de inflação é necessário e inerente a dinâmica social e econômica do país, pois, "as tentativas dos países em via de desenvolvimento de alcançar estágios mais avançados de crescimento econômico, dificilmente se realizam sem que também 
A relação entre o comportamento do indicador de liquidez corrente das empresas de capital aberto do agronegócio pela variação de índices econômicos no Brasil

ocorram concomitantemente, elevações no nível geral de preços".

Com o exposto, para entender o impacto da inflação no agronegócio, Serigati (2013) explicou que é preciso delimitar qual a natureza do processo inflacionário (de custos ou de demanda?). Pois, enquanto um aumento da demanda impulsiona para cima o preço dos produtos agrícolas (melhorando a margem de lucro do agricultor), a elevação dos custos dos insumos utilizados para a produção põe o produtor em dificuldade, pois segundo o autor é quase nula sua influência sobre o preço do produto final, fazendo com que a atividade agrícola tenha que absorver esta elevação.

Segundo Barros (2017) mesmo com as intempéries econômicas que o país experimentou nos últimos anos, o agronegócio tem sido resistente, e o impacto disto nas empresas do setor tem sido minimizado. Isto porque "o setor opera numa perspectiva de longo prazo, mantendo o contínuo empenho na busca de produtividade e eficiência, o que tem garantido um crescimento sustentável ao longo de décadas, sem pressão importante sobre os seus preços relativos - e, portanto, sobre a inflação - no mercado interno" (BARROS, 2017, p. 1).

Os aspectos econômicos anteriores, dão conta das interações teóricas e empíricas do contexto do agronegócio dentro de um ambiente macroeconômico, pela análise dos índices de inflação, juros, câmbio e riqueza nacional. No entanto as relações dos indicadores econômico-financeiros das empresas do setor também estão sujeitas às variações em nível microeconômico, e para isso foram aglutinadas variáveis desta esfera, e também apresentadas a seguir.

Para isto foram adotados dois grupos de variáveis independentes calculadas e disponibilizadas por CEPEA (2017) e FIESP (2017). O primeiro grupo expõe os índices relativos ao contexto microeconômico específico do agronegócio (PIB-AGRO, PIB-AGRI, PIB-PEC, SBC-AGRO) e o segundo grupo são índices relativos à atividade do setor no mercado externo (IC-AGRO, IPE-AGRO, IVE-AGRO, IAT-AGRO), respectivamente nos Quadros 2 e 3.

Quadro 2 - Índices Relativos ao Contexto Microeconômico do Agronegócio

\begin{tabular}{|c|c|}
\hline Variável & Significado \\
\hline $\begin{array}{l}\text { PIBAGRO } \quad-\text { PIB } \\
\text { Agronegócio - Índice de } \\
\text { Variação Percentual ao } \\
\text { Ano-CEPEA (2017). }\end{array}$ & $\begin{array}{l}\text { "Pelo critério metodológico do Cepea/Esalq-USP, o PIB do agronegócio é medido pela ótica do } \\
\text { produto, ou seja, pelo Valor Adicionado (VA) total deste setor na economia. [...] O PIB do } \\
\text { agronegócio brasileiro refere-se, portanto, ao produto gerado de forma sistêmica na produção de } \\
\text { insumos para a agropecuária, na produção primária e se estendendo por todas as demais atividades } \\
\text { que processam e distribuem o produto ao destino final" (CEPEA, 2017, p. 2). }\end{array}$ \\
\hline $\begin{array}{l}\text { PIBAGRI - PIB Ramo } \\
\text { Agrícola }- \text { Índice de } \\
\text { Variação Anual - CEPEA } \\
\text { (2017). }\end{array}$ & $\begin{array}{l}\text { "No ramo agrícola, o PIB é "acompanhado" por meio de } 17 \text { cadeias primárias, } 10 \text { produtos } \\
\text { industriais (agregados), além das atividades industriais produtoras de insumos, mas todas as demais } \\
\text { atividades, ainda que não acompanhadas, são consideradas no cômputo do valor do PIB" (CEPEA, } \\
\text { 2017). }\end{array}$ \\
\hline $\begin{array}{l}\text { PIBPEC - PIB Ramo } \\
\text { Pecuária - Índice de } \\
\text { Variação Anual - CEPEA } \\
\text { (2017). }\end{array}$ & $\begin{array}{l}\text { "No ramo pecuário, o acompanhamento se dá a partir do desemprenho de cinco atividades primárias, } \\
\text { que fornecem matéria-prima para três grupos de produtos agroindustriais, além das atividades } \\
\text { industriais produtoras de insumos para a pecuária" (CEPEA, 2017). }\end{array}$ \\
\hline $\begin{array}{l}\text { SBCAGRO - Saldo da } \\
\text { Balança Comercial do } \\
\text { Agronegócio - Variação } \\
\% \text { média anual - FIESP } \\
(2016) \text {. }\end{array}$ & $\begin{array}{l}\text { Em seu cálculo são considerados tudo o que os ramos agrícola e pecuário importam como } \\
\text { insumos para a produção, matéria prima para agroindústrias e commodities para abastecer o } \\
\text { mercado interno, sendo também considerados neste cálculo todos os valores que os } \\
\text { componentes desta cadeia produtiva recebem ao exportarem sua produção. (FIESP, 2017). }\end{array}$ \\
\hline
\end{tabular}

Fonte: Elaborado pelos autores (2018).

Com base nas proposições esclarecidas no Quadro 2, percebe-se que estes índices microeconômicos contribuem para o desenho geral do cenário econômico do agronegócio e consequentemente mantém relação com as empresas do setor.

Ressalta-se também que a pertinência em analisá-los, se dá uma vez que alguns centros de pesquisa (CEPEA, 2017; FIESP, 2017), têm se dedicado a explicar sua evolução no contexto do agronegócio, mas são inexistentes as análises de comparações com o desempenho das empresas deste, ou de outro setor (HERCOS JUNIOR, 2009; SERIGATI, 2013).

O último grupo de índices relacionados ao agronegócio é calculado pelo CEPEA (2017), apresentado no Quadro 3, e mede a atividade do setor por sua interação com o mercado externo. O último grupo de índices expostos no Quadro 3, segundo sua natureza, foi dividido em duas partes, a que expressa valor e a que expressa o volume das atividades de exportação. "Os índices de valor são: 
IPE-Agro/Cepea, IC-Agro/Cepea e o IAT-Agro/Cepea; e o índice de volume o IVE-Agro/Cepea" (CEPEA, 2017, p. 3).

O CEPEA (2017) ainda explicou que tanto o IPE-AGRO, quanto o IC-AGRO, são índices que fornecem importantes evidências sobre a formação de preço daquilo que é pago ao produtor brasileiro no momento da exportação, e enquanto os dois primeiros índices citados dão base a uma análise da evolução econômica do setor, o IAT-AGRO e o IVE-AGRO fornecem informações de cunho operacional (CEPEA, 2016).

Quadro 3 - Índices Relativos a Atividade do Setor com o Mercado Externo

\begin{tabular}{|l|l|}
\hline Variável & Significado \\
\hline $\begin{array}{l}\text { IPE-AGRO } \\
\text { Variação \% média } \\
\text { anual - CEPEA } \\
(2016) .\end{array}$ & $\begin{array}{l}\text { "Este índice considera os preços em dólares FOB (incluem custos de transporte até o navio que segue para } \\
\text { o país importador) das exportações do agronegócio brasileiro, incluindo produtos agropecuários in natura e } \\
\text { processados. Ou seja, refere-se aos preços unitários recebidos pelos exportadores por categoria de produto } \\
\text { [...]. Para compor o índice foram selecionados os produtos classificados como componentes do } \\
\text { agronegócio, descritos no Sistema de Importações e Exportações do Agronegócio do Instituto de Economia } \\
\text { Agrícola (IEA, 2002). [...]" (CEPEA, 2017, p. 1) }\end{array}$ \\
\hline $\begin{array}{l}\text { IC-AGRO } \\
\text { Variação \% média } \\
\text { anual - CEPEA } \\
\text { (2016). }\end{array}$ & $\begin{array}{l}\text { "Representa uma média ponderada das taxas de câmbio, em valores reais, dos 10 parceiros comerciais do } \\
\text { Brasil mais importantes. A taxa efetiva de câmbio representa uma cesta de moedas estrangeiras em que o } \\
\text { brasileiro. A ponderação é calculada anualmente com base na participação dos 10 principais países nos } \\
\text { últimos 3 anos. Foram utilizados os dados disponíveis para: Estados Unidos, Japão, Alemanha, Países Baixos } \\
\text { (Holanda), Itália, Argentina, França, Reino Unido, Canadá, Chile, Espanha, Paraguai e China para os anos } \\
\text { de 1989 a 1995; de acordo com a participação de cada país nas exportações do Brasil" (CEPEA, 2017, p. 2). }\end{array}$ \\
\hline $\begin{array}{l}\text { IAT-AGRO } \\
\text { Variação \% média } \\
\text { anual - CEPEA } \\
\text { (2016). }\end{array}$ & $\begin{array}{l}\text { "Representa o preço em Reais das exportações e seu cálculo resulta da multiplicação dos dois índices } \\
\text { anteriores. Assim, a atratividade das exportações pode crescer tanto porque os preços em dólares (IPE-Agro/ } \\
\text { Cepea) cresceram, como porque o Real desvalorizou em relação às outras moedas (ICAgro/Cepea) } \\
\text { (CEPEA, 2017, p. 2). }\end{array}$ \\
$\begin{array}{l}\text { Variação \% média } \\
\text { anual - CEPEA } \\
\text { (2016). }\end{array}$ & $\begin{array}{l}\text { "Mede a evolução do volume físico de exportações do agronegócio brasileiro. Para seu cálculo, são coletadas } \\
\text { informações do sistema AliceWeb, da Secex2” (CEPEA, 2017, p. 2). }\end{array}$ \\
\hline
\end{tabular}

Fonte: Elaborado pelos autores (2017), com base em CEPEA (2017).

Com o exposto neste tópico do referencial, foram apresentas as exposições teóricas e empíricas a respeito dos índices econômicos (nível de atividade econômica, taxa de câmbio, taxa de juros e inflação) que serviram de base para se extraírem os contextos macroeconômicos, microeconômicos e de atividade do setor com o mercado externo. No tópico seguinte serão apresentadas as nuances teóricas e empíricas a partir do ILC, que serão postas em relação aos índices econômicos apresentados até aqui.

\subsection{Aspectos Teóricos e Empíricos sobre a Análise do Indicador de Liquidez Corrente}

A utilização da análise de balanços como esclarecedora do comportamento dos indicadores econômico-financeiros, foi conceituada por Iudícibus (2009, p. 5) como a "arte de saber extrair relações úteis, para o objetivo econômico que tivermos em mente".

Esta técnica de monitoramento do comportamento dos negócios se modernizou ao longo do tempo e segundo Horrigan (1968) acompanhou as revoluções industriais do fim do século XIX e do início do século XX, conduzindo as demonstrações contábeis a um denominador comum da dinâmica da empresa, estabelecendo assim bases de comparações semelhantes para negócios e setores de atuações distintas.

Esta evolução e padronização das informações contábeis reportadas pelas demonstrações financeiras contribuíram para que os analistas começassem a utilizar estes dados como fonte de previsão do comportamento futuro do negócio e de monitoramento do desempenho passado, pois segundo Beaver (1966) através destes dados os gestores começariam a identificar ações futuras com certa antecedência e confiabilidade. Logo, para alcançar-se este aspecto de previsão, Shashua e Goldschmidt (1974) sugeriram que a sofisticação do cálculo dos indicadores, muitas vezes afastou este poder preditivo, por se incluírem variáveis muito específicas que podem não influenciar outros contextos.

Dentro desta análise estão os indicadores de liquidez, que Marion (2009) evidenciou como primeiro objetivo, o de esclarecer a capacidade de pagamento do negócio, saldando os compromissos assumidos no 
A relação entre o comportamento do indicador de liquidez corrente das empresas de capital aberto do agronegócio pela variação de índices econômicos no Brasil

curto e no longo prazo, com os recursos presentes no ativo.

Expandindo esta análise, Martins, Diniz e Miranda (2014) explicaram que ao analisar o empreendimento pela ótica dos indicadores de liquidez, o pesquisador está evidenciando também a capacidade da empresa em continuar sua operação, pois a partir do comportamento destes indicadores, pode-se esclarecer a saúde financeira do empreendimento com relação aos compromissos firmados com terceiros.

É neste contexto teórico que se insere o Indicador de Liquidez Corrente. Coelho (2012), utilizandoo empiricamente, o definiu como a razão entre o ativo circulante e o passivo circulante, endossado por Assaf Neto (2006) que explicou que o ILC, é um indicador que evidencia o quanto existe de ativo circulante em termos monetários, para cada unidade de obrigações de curto prazo da empresa. Assim, no ILC utilizamse todos os recursos de curto prazo no numerador, conforme a fórmula e significado apresentado no Quadro 4.

Quadro 4 - Indicador de Liquidez Corrente, Fórmula e Conceito

\begin{tabular}{|c|c|c|}
\hline Indicador & Fórmula & Significado \\
\hline $\begin{array}{l}\text { Liquidez } \\
\text { Corrente }\end{array}$ & $\frac{\text { Ativo Circulante }}{\text { Passivo Circulante }}$ & $\begin{array}{c}\text { Demonstra o montante de recursos de } \\
\text { curto prazo que a empresa detém, para } \\
\text { satisfazer obrigações de curto prazo. }\end{array}$ \\
\hline
\end{tabular}

Fonte: Elaborado pelos autores (2017), com base em Martins, Diniz e Miranda (2014).

Pelo exposto, observa-se que o ILC carrega em sua análise a capacidade de demonstrar se existem recursos de curto prazo no ativo, suficientes para saldar as obrigações de curto prazo da empresa presentes no passivo (MARTINS; DINIZ, MIRANDA, 2014). Dando assim ao gestor, uma noção existência de alguma sobra financeira de recursos líquidos para manter o giro operacional do negócio no curto prazo.

As interações teóricas do ILC expostas até aqui, foram testadas anteriormente em outros contextos, geográficos, econômicos, políticos e sociais, e representam os estudos correlatos que evidenciaram uma série de achados empíricos sobre a relação deste indicador a algum contexto econômico. Assim evidenciados os significados e fórmula de cálculo do indicador, apresentam-se a seguir, alguns resultados de pesquisas que conduziram uma investigação semelhante e que serviram de base de comparação para as discussões dos resultados neste artigo.

Empiricamente, Coelho (2012) utilizou como amostra dados de 141 empresas brasileiras de capital aberto listadas entre 2003 a 2011 e que não atuavam nem no setor financeiro, nem no setor de seguros. Buscando estabelecer a relação entre variáveis macroeconômicas e o desempenho das empresas, a autora identificou que as variáveis inflação e taxa de câmbio se correlacionaram ao indicador de liquidez corrente de forma negativa. E para as variáveis PIB e Taxa de Juros a relação encontrada foi direta, ou positiva. Assim, no período de crescimento econômico a variação positiva do PIB e da Taxa de Juros, foi benéfica para o incremento da sobra financeiro de curto prazo das empresas de capital aberto brasileiras.

No setor da indústria química, que mantem relação com o agronegócio pelo fornecimento de insumos à cadeia, Santos et al. (2008) correlacionando variáveis macroeconômicas a indicadores de liquidez, rentabilidade, estrutura de capital e mercado/risco, identificaram que para a liquidez corrente, a indústria química apresentou uma relação positiva ao PIB do país, mas contrária ao câmbio, sinalizando um incremento da dívida em épocas de queda da economia e uma sobra financeira quando a economia está aquecida.

Buscando relacionar variáveis macroeconômicas (cotação do real em relação ao dólar, inflação, risco Brasil, taxa de juros, balança comercial, PIB brasileiro e mundial), também aos indicadores de liquidez, Hercos Junior (2009) em uma análise limitada a apenas uma empresa do setor de tecnologia, identificou que entre 2003 e 2006 os fatores macroeconômicos foram favoráveis à atuação do setor. O autor salientou que mesmo com altos índices de endividamento e baixos índices de liquidez corrente, que a empresa conseguiu continuar atuando no mercado, devido o contexto macroeconômico positivo para o setor de tecnologia. Com isso, o autor levanta a necessidade de entendimento do setor de modo isolado, pois as relações significativas podem ser específicas do setor.

Analisando a relação entre diferentes grupos de indicadores econômico-financeiros, Bastos et al. (2009), analisaram os determinantes da estrutura de capital de 388 empresas listadas nas bolsas do Brasil, Argentina, Chile, México e Peru. Os autores identificaram que o indicador de liquidez corrente, foi um dos fatores específicos da empresa que mais ajudou a determinar sua estrutura de capital. Assim a evidência de 
relação estatística entre os indicadores de liquidez e os de endividamento foi positiva. Com isso os autores salientaram que as variáveis que influenciam a estrutura de capital, também podem se relacionar de modo significativo ao indicador de liquidez corrente das empresas.

Pandini et al. (2017), conduziram uma pesquisa que objetivou verificar o impacto das variáveis macroeconômicas nos indicadores econômico-financeiros de 103 empresas dos setores de Consumo Cíclico e Não Cíclico da B3, (antiga BM\&FBovespa) listadas entre 2008 e 2015. Analisando os coeficientes de correlação canônica, constataram a existência de relação diretamente proporcional da Taxa de Câmbio, do PIB, e da Taxa SELIC (juros) com a Liquidez Corrente, logo o aumento de uma das variáveis está relacionado ao aumento do indicador.

Semelhante a investigação desta pesquisa, porém utilizando métodos estatísticos e grupos de empresas distintos, Silva et al. (2017) correlacionaram variáveis macroeconômicas a indicadores contábeis de empresas brasileiras de capital aberto, listadas entre 2010 e 2016. Para as empresas listadas no setor de bens industriais e consumo cíclico, os autores identificaram que a Liquidez Corrente apresentou comportamento inversamente proporcional à taxa de câmbio, e ainda no setor de consumo cíclico, a Liquidez Corrente se correlacionou à taxa de juros positivamente.

Evidenciadas as acepções teóricas e empíricas levantadas neste tópico, elas serão utilizadas como embasamento para as discussões dos resultados acerca da relação levantada entre o ILC das empresas do agronegócio e os índices econômicos na seção de resultados. Traçados os paralelos entre os achados empíricos e os aspectos conceituais dos indicadores de liquidez e das variáveis macroeconômicas relacionadas, com base nestas proposições teóricas e empíricas apresentadas, encerra-se neste tópico a parte teórica do estudo e na seção seguinte são apresentadas as pertinências metodológicas que suportam a operacionalização dos resultados e discussões deste estudo.

\section{Aspectos Metodológicos}

Para as Ciências Sociais Aplicadas dentro da qual se insere a Contabilidade, o arcabouço metodológico é amplo, e existe embasamento procedimental e técnico disponível e aceito para diversos tipos de pesquisa (BARROS; LEHFELD, 2007; MARTINS; THEOPHILO, 2009; RAUPP; BEUREN, 2004; VERGARA, 2009). Lastreado nestes embasamentos, ressalta-se que esta é uma pesquisa aplicada, documental, que utiliza do método descritivo, empírico-positivista com delineamento ex post facto, e abordou de modo quantitativo os objetivos propostos.

Para a coleta de dados, este estudo utilizou um recorte longitudinal entre 2010 e 2016, que conforme Rajulton (2001, p. 177) "é essencial se quisermos determinar a relação de condições, agindo durante um período de tempo, sobre os mesmos indivíduos". Trabalhando-se com este horizonte temporal, por se tratar do período quando por força da convergência e harmonização aos padrões e normas contábeis internacionais - imposta pela Lei 11.638 de 2007 (que alterou a Lei 6.404 de 1976 (Lei das Sociedades por Ações)) sob a tutela da Instrução CVM (Comissão de Valores Mobiliários) no 457 de 2007 -, as empresas de capital aberto estariam obrigadas à partir de 2010, a elaborarem e divulgarem seus demonstrativos consolidados, baseando-se para isso no padrão contábil internacional emitido pelo International Accounting Standards Board (IASB).

Buscou-se também reduzir a presença de outliers para se alcançar a homogeneidade dos dados, utilizando também como critérios de permanência das empresas na amostra, a auto declaração de participação à cadeia do agronegócio, a disponibilidade dos demonstrativos contábeis no sistema Economática ${ }^{\circledR}$, o registro ativo na B3, antiga BM\&FBovespa, para todo o período analisado (2010 a 2016) e a adequação quanto à proposição do CEPEA (2014) sobre a alocação do percentual de atividades dos segmentos onde atuam as empresas, conforme o Quadro 5.

Com base no Quadro 5, por terem uma relação mais ampla com o setor, escolheu-se adotar como empresa aderente a amostra, aquelas que dedicam no mínimo sessenta por cento (60\%) de suas atividades ao agronegócio (CEPEA, 2014). A partir disso, verificou-se que atuando diretamente na agricultura e pecuária, ou produzindo e consumindo insumos do setor, existe uma amostra inicial composta por 20 segmentos da B3 (2017), onde 82 empresas listadas conservaram relação com a cadeia produtiva do setor no período. 
A relação entre o comportamento do indicador de liquidez corrente das empresas de capital aberto do agronegócio pela variação de índices econômicos no Brasil

Quadro 5 - Atividades e suas participações no Agronegócio

\begin{tabular}{|c|c|c|}
\hline ATIVIDADES & SEGMENTOS & $\begin{array}{c}\text { \% DAS ATIVIDADES ALOCADAS NO } \\
\text { AGRONEGÓCIO }\end{array}$ \\
\hline Agronegócio, Agricultura, Silvicultura e Pesca & Agropecuária & 100 \\
\hline Pecuária e Pesca & Agropecuária & 100 \\
\hline Indústria Café & Agroindústria & 100 \\
\hline $\begin{array}{l}\text { Beneficiamento de Produtos Vegetais (Arroz, Trigo, } \\
\text { Mandioca, Milho) }\end{array}$ & Agroindústria & 100 \\
\hline Móveis de Madeira & Agroindústria & 100 \\
\hline Abate e Preparação de Carnes & Agroindústria & 100 \\
\hline Laticínios & Agroindústria & 100 \\
\hline Açúcar & Agroindústria & 100 \\
\hline Óleo Vegetal (Exceto Milho) e Farelo & Agroindústria & 100 \\
\hline Pães, Massas, Doces, Bebidas & Agroindústria & 100 \\
\hline Fumo & Agroindústria & 100 \\
\hline Têxtil & Agroindústria & 48,5 \\
\hline Vestuário e Acessórios & Agroindústria & 36,4 \\
\hline Produtos de Madeira & Agroindústria & 62,5 \\
\hline Papel e Celulose & Agroindústria & 100 \\
\hline Etanol & Agroindústria & 100 \\
\hline Medicamentos Veterinários & Agroindústria & 100 \\
\hline Fertilizantes & Insumos & 100 \\
\hline Refino Petróleo (Óleo Diesel) & Insumos & 9,5 \\
\hline Serviços de Comercialização & Serviços & 14,5 \\
\hline
\end{tabular}

Fonte: CEPEA (2014, p. 5) com base em dados de IBGE, CNAE, RAIS.

Em seguida, demonstraram-se quais empresas apresentaram dados na plataforma Economática ${ }^{\circledR}$ para o período de 2010 a 2016 . E depois de aplicados os critérios de permanência da empresa no banco de dados, a amostra final foi composta por dados de 33 empresas (Grupo Geral), sendo 13 do Grupo Extra e 20 do Grupo Intra conforme pode ser verificado na Coluna 1 do Quadro 6 na página seguinte.

Quadro 6 - Setores, Segmentos e Grupos de Empresas da Amostra da Pesquisa

\begin{tabular}{|c|c|c|c|}
\hline Grupo & Setor & Segmento & Razão Social da Empresa \\
\hline \multirow{13}{*}{ 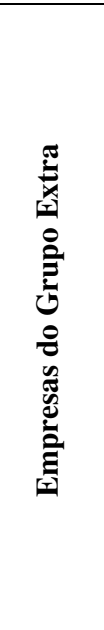 } & \multirow{13}{*}{ Bens Industriais } & Máquinas e Equipamentos Agrícolas & Metisa Metalurgica Timboense S.A. \\
\hline & & \multirow{5}{*}{ Material Rodoviário } & Fras-Le S.A. \\
\hline & & & Wetzel S.A. \\
\hline & & & Randon S.A. Implementos E Participacoes \\
\hline & & & Recrusul S.A. \\
\hline & & & Tupy S.A. \\
\hline & & \multirow{3}{*}{ Serviços De Apoio E Armazenagem } & Prumo Logistica S.A. \\
\hline & & & Santos Brp S.A. \\
\hline & & & Wilson Sons S.A. \\
\hline & & Transporte Ferroviário & Rumo S.A. \\
\hline & & \multirow{2}{*}{ Transporte Hidroviário } & Log-In Logistica Intermodal S.A. \\
\hline & & & Trevisa Investimentos S.A. \\
\hline & & Transporte Rodoviário & Jsl S.A. \\
\hline
\end{tabular}




\begin{tabular}{|c|c|c|c|}
\hline Grupo & Setor & Segmento & Razão Social da Empresa \\
\hline \multirow{21}{*}{ 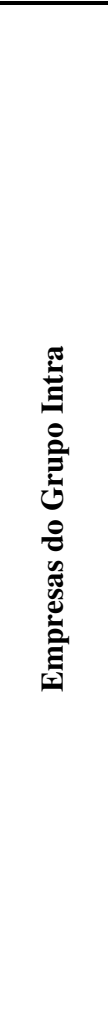 } & \multirow{14}{*}{$\begin{array}{l}\text { Consumo Não } \\
\text { Cíclico }\end{array}$} & \multirow{4}{*}{ Agricultura } & Brasilagro Companhia Braslr Propds Agrcl S.A. \\
\hline & & & Pomifrutas S.A. \\
\hline & & & Slc Agricola S.A. \\
\hline & & & Terra Santa S.A. \\
\hline & & Açúcar E Álcool & São Martinho S.A. \\
\hline & & \multirow{2}{*}{ Alimentos Diversos } & Josapar Joaquim Oliveira S.A. \\
\hline & & & M. Dias Branco Sa Ind Com De Alimento \\
\hline & & \multirow{5}{*}{ Carnes E Derivados } & Minerva S.A. \\
\hline & & & Brf S.A. \\
\hline & & & Jbs S.A. \\
\hline & & & Minupar Participacoes S.A. \\
\hline & & & Marfrig Global Foods S.A. \\
\hline & & Cervejas E Refrigerantes & Ambev S.A. \\
\hline & & Produtos De Uso Pessoal & Natura Cosmeticos S.A. \\
\hline & \multirow{6}{*}{ Materiais Básicos } & \multirow{2}{*}{ Madeira } & Duratex S.A. \\
\hline & & & Eucatex S.A. Industria E Comercio \\
\hline & & \multirow{4}{*}{ Papel E Celulose } & Fibria Celulose S.A. \\
\hline & & & Klabin S.A. Brazilian Units \\
\hline & & & Suzano Papel E Celulose S.A. \\
\hline & & & Sansuy S.A. Indústria De Plásticos \\
\hline & 3 SETORES & 16 SEGMENTOS & 33 \\
\hline
\end{tabular}

Fonte: Elaborado pelos autores com base em B3 (2017) e Economática (2016).

Com base na amostra evidenciada no Quadro 6 e de posse das conceituações do CEPEA (2014) quanto à atuação das empresas no setor, para efeito de análise dos resultados, as 33 empresas foram separadas em três grupos: Grupo Geral, Grupo Extra e Grupo Intra. As empresas do Grupo Geral foram todas as 33 empresas presentes no Quadro 6, e a partir delas é que foram extraídas as relações das variáveis macroeconômicas com os indicadores das empresas listadas no setor. Já o Grupo Extra, foi composto por 13 empresas do Setor de Bens Industriais, que segundo CEPEA (2014) atuam da "porteira para fora" das propriedades rurais, em atividades de suporte ao agronegócio. E a análise intrasetorial, foi conduzida a partir das 20 empresas dos Setores de Consumo Não Cíclico e Materiais Básicos, representando as empresas que atuam diretamente nesta cadeia produtiva.

Assim, com o uso dos dados das empresas da amostra (Quadro 6), resumiram-se os demonstrativos contábeis, extraíram-se deles o Indicador de Liquidez Corrente como variável dependente (MARTINS; DINIZ; MIRANDA, 2014) e investigou-se sua relação com o contexto estabelecido em três (3) grupos de índices econômicos: macroeconômicos, microeconômicos e de atividades do setor com o mercado externo, como variáveis independentes.

Cada um dos três grupos de índices econômicos foi explicado e abordado no referencial teórico desta pesquisa e foram operacionalizados a partir do seguinte modelo econométrico, pelo método da Análise de Regressão Linear Múltipla com a técnica de Análise de Dados em Painel.

Equação 1 - Indicador de Liquidez Corrente versus Variáveis Independentes

INDICADOR DE LIQUIDEZ CORRENTE $_{i t}=\alpha_{i}+\beta_{1}$ PIB $_{i j}+\beta_{2}$ TAXSELIC $_{i j}+\beta_{3}$ TAXCAMB $_{i j}+\beta_{4}$ IPCA $_{i j}+\beta_{5}$ PIBAGRI $_{i j}$ $+\beta_{6}$ PIBPEC $_{\mathrm{ij}}+\beta_{7}$ SBCAGRO $_{\mathrm{ij}}+\beta_{8}$ IPE-AGRO ${ }_{\mathrm{ij}}+\beta_{9}$ IC-AGRO $_{\mathrm{ij}}+\beta_{10}$ IAT-AGRO $_{\mathrm{ij}}+\beta_{11}$ IVE-AGRO $_{\mathrm{ij}}+\beta_{12}$ PIBAGRO $_{\mathrm{ij}}+$ $\varepsilon_{\mathrm{ij}}$

Legenda: IC it: Indicador Contábil da empresa i no ano j (Substituir pelos Indicadores de liquidez, administração do capital de giro e estrutura patrimonial); $\alpha_{\mathrm{i}}$ : intercepto; $\beta_{1}$ : Coeficiente Linear Referente a Variável PIB; PIB $\mathrm{ij}_{\mathrm{ij}}$ : Produto Interno Bruto do Brasil i no ano $\mathrm{j} ; \beta_{2}$ : Coeficiente Linear Referente a Variável TAXSELIC; TAXSELIC $\mathrm{ij}_{\mathrm{j}}$ : Taxa Básica de Juros SELIC no Brasil i no ano j; $\beta_{3}$ : Coeficiente Linear Referente a Variável TAXCAMB; TAXCAMB ${ }_{\mathrm{ij}}$ : Taxa de Câmbio do Brasil i no ano j; $\beta_{4}$ : Coeficiente Linear Referente a Variável IPCA; IPCA $\mathrm{ij}_{\mathrm{j}}$ : Índice de Preços ao Consumidor Brasileiro i no ano j; $\beta_{5}$ : Coeficiente Linear Referente a Variável PIBAGRI; PIBAGRI $\mathrm{ij}_{\mathrm{j}}$ : Produto Interno Bruto da Agricultura no Brasil i no ano j; $\beta_{6}$ : Coeficiente Linear Referente a Variável PIBPEC; PIBPEC $\mathrm{ij}$ : Produto Interno Bruto da Pecuária no Brasil i no ano j; $\beta_{7}$ : Coeficiente Linear Referente a Variável SBCAGRO; SBCAGRO $\mathrm{ij}$ : Saldo da Balança Comercial do Agronegócio Brasileiro i no ano j; $\beta 8$ : Coeficiente Linear Referente a 
A relação entre o comportamento do indicador de liquidez corrente das empresas de capital aberto do agronegócio pela variação de índices econômicos no Brasil

Variável IPE-AGRO; IPE-AGRO ${ }_{\mathrm{ij}}$ : Índice de Preços de Exportação do Agronegócio Brasileiro i no ano j; $\beta_{9}$ : Coeficiente Linear

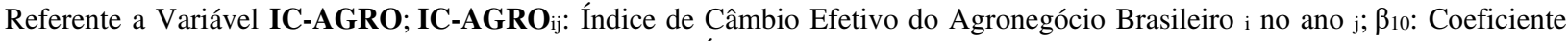
Linear Referente a Variável IAT-AGRO; IAT-AGRO ${ }_{\mathrm{ij}}$ : Índice de Atratividade das Exportações do Agronegócio Brasileiro i no ano j; $\beta_{11}$ : Coeficiente Linear Referente a Variável IVE-AGRO; IVE-AGRO ${ }_{\mathrm{ij}}$ : Índice de Volume de Exportações do Agronegócio Brasileiro i no ano j; $\beta_{1} 2$ : Coeficiente Linear Referente a Variável PIBABRO; PIBAGRO no Brasil i no ano j; $\varepsilon_{\mathrm{ij}}$ : Erro Aleatório.

Para operacionalizar-se este modelo econométrico, como forma de padronizar as variáveis que compõe o banco de dados, foram aplicados dois procedimentos, a winsorização e a transformação logarítmica. Identificando dentro de cada um dos indicadores econômico-financeiros, os valores que se destoaram muito em torno de sua própria média. Operacionalizou-se a winsorização, e delimitou-se nas distribuições de frequência os valores localizados a $2 \%$ das distribuições caudais, utilizando como base, os extremos definidos nos percentis $2 \%$ e $98 \%$. Este procedimento (CUPERTINO, 2013) foi utilizado para neutralizar nas variáveis dependentes, o impacto dos outliers nos outputs dos programas estatísticos utilizados.

Depois da winsorização, foi aplicada a transformação logarítmica na base 10, para ambos os grupos de variáveis (dependentes e independentes). Ayres et al. (2007), explicaram que esta transformação é indicada quando os valores de uma distribuição linear são considerados assimétricos, para tornar os valores positivos assimétricos "próximos a uma distribuição normal".

Conduzidos os procedimentos de adequação das variáveis que compuseram o banco de dados, realizouse a análise estatística (FÁ VERO et al., 2009) dos valores máximos, mínimos, média, desvio padrão e coeficiente de variação dos indicadores econômico-financeiros. No segundo passo da análise estatística do comportamento dos dados, buscou-se evidenciar como aconteceu a relação entre as variáveis dependentes e independentes, operacionalizando-se a matriz de correlação como pressuposto básico das pesquisas quantitativas (FÁVERO et al. 2009).

Demonstrados os procedimentos estatísticos (Análise Descritiva e Matriz de Correlação) que abordaram as variáveis de modo a construir um panorama geral do contexto analisado, apresenta-se a seguir o método utilizado para se construir relações mais específicas entre o ILC e os índices econômicos, a Análise de Dados em Painel.

Nesta pesquisa, adotou-se o Modelo de Regressão Linear Múltipla de Análise de Dados em Painel Balanceado, pois segundo Fávero et al. (2009), todos os recortes transversais, tanto dos indicadores contábeis, quanto das variáveis macroeconômicas, apresentaram todas as observações no período de analisado.

Assim, para a condução da Análise de Dados em Painel, utilizou-se o software gratuito e livre GRETL Versão 2017b, idealizado por Cottrel (2011). E para o uso desta técnica foram adotados os pressupostos apresentados por Fávero et al. (2009), Gujarati e Porter (2011), Wooldridge (2010), e trabalhados por Costa (2017) e Soares e Funchal (2008). Com isso, a operacionalização desta pesquisa, pode ser visualizada no desenho de pesquisa da Figura 2.

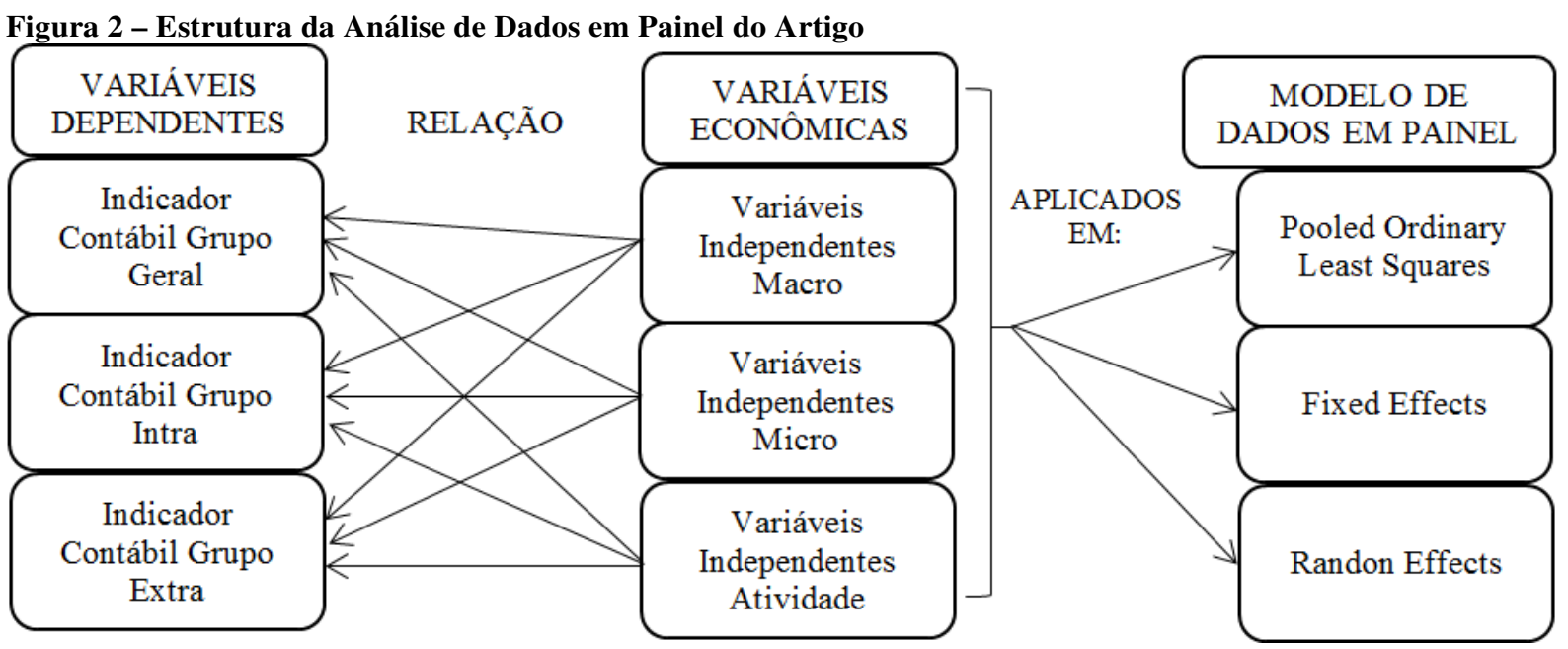

Fonte: Elaborado pelos autores (2018).

O aspecto metodológico geral do trabalho fica por conta do levantamento da relação do ILC 
de três grupos de empresas do agronegócio listadas na B3, pela variação de três grupos de índices econômicos, operacionalizados com a aplicação de três modelos de Análise de Dados em Painel, conforme a Figura 2.

\section{Resultados e Discussões}

\subsection{Análise das Estatísticas Descritivas e da Correlação Linear do ILC das Empresas}

No primeiro tópico desta seção são apresentadas as análises das estatísticas descritivas, explicando o comportamento do Indicador de Liquidez Corrente (variável dependente). Para isso, elaborou-se um panorama da situação econômico-financeira das empresas da amostra a partir de suas estatísticas descritas, conforme os resultados da Tabela 1.

Tabela 1 - Estatísticas Descritivas do ILC das 33 Empresas da Amostra entre 2010 e 2016

\begin{tabular}{c|c|c|c|c|c}
\hline Variável & MÁX & MÍN & MÉD & DVP & CV \\
\hline ILC & 4,1231 & 0,0121 & 1,5734 & 0,7799 & $49,57 \%$
\end{tabular}

Legenda: ILC: Indicador de Liquidez Geral; MÁX: Valores Máximos: MIN: Valores Mínimos; MÉD: Média; DVP: Desvio Padrão; CV: Coeficiente de Variação.

Fontes: resultados da pesquisa, elaborado pelos autores (2018).

Observa-se na Tabela 1, que o ILC informa um setor do agronegócio com boa saúde econômicofinanceira, que na média evidência a existência de uma folga financeira de curto prazo para o setor. Sobre o indicador, recorda-se que Coelho (2012) o definiu como a razão entre o ativo circulante e o passivo circulante. Assim, os resultados da pesquisa para este indicador são que, para cada $R \$ 1,00$ de obrigações de curto prazo, o setor do agronegócio apresenta em média $\mathrm{R} \$ 1,57$ de ativos circulantes. Por isso pode-se afirmar que na média, há uma sobra $(\mathrm{R} \$ 0,57)$ de recursos de curto prazo, para cada real assumido com obrigações de curto prazo para as empresas do setor do agronegócio.

O resultado anterior está posto em relação à média, mas como um setor de atuação diversificada (CEPEA, 2017), as empresas da amostra que atuam no agronegócio brasileiro contribuem para um alto coeficiente de variação (CV) e valores máximos e mínimos destoantes em torno dela. Assim este resultado pode ser explicado, e em parte já havia sido previsto na literatura, pois conforme Hall et al. (2011), a aderência de uma determinada empresa à cadeia do agronegócio, não cessa na identificação de sua atuação direta no setor, pois no agronegócio, observa-se uma heterogeneidade endógena à cadeia, pois as empresas agrícolas, pecuárias e agroindustriais dos mais diversos seguimentos, atuam em um mesmo contexto produtivo.

Realizadas as análises das estatísticas descritivas das variáveis dependentes e independentes, antes de partir para a análise dos modelos de regressão de dados em painel, realizou-se a análise das estimativas de Correlação Linear, a partir dos dados apresentados na Tabela 2.

Tabela 2 - Matriz de Correlação Linear das Variáveis Macroeconômicas Versus o ILC

\begin{tabular}{ccccccccccccc} 
& PIB & IPCA & TCB & TSEC & PIBO & PIBI & PIBPC & SBCA & IPE & IC & IAT & IVE \\
\hline \multirow{2}{*}{ CCL } & $\mathbf{0 , 1 3 2}$ & $\mathbf{- 0 , 1 2 5}$ & $-0,099$ & $-0,062$ & 0,099 & 0,080 & 0,085 & $\mathbf{0 , 1 0 9}$ & 0,102 & $\mathbf{- 0 , 1 2 9}$ & $-0,007$ & 0,023 \\
\hline \multirow{2}{*}{ p-valor } & $\mathbf{( 0 , 0 4 5 )}$ & $\mathbf{( 0 , 0 5 9 )}$ & 0,135 & 0,346 & 0,134 & 0,222 & 0,197 & $\mathbf{( 0 , 0 9 8})$ & 0,120 & $\mathbf{( 0 , 0 5 2})$ & 0,918 & 0,723 \\
\hline
\end{tabular}

Legenda: CCL: Coeficiente de Correlação Linear; ILC: Indicador de Liquidez Corrente; PIB: Produto Interno Bruto; IPCA: Índice de Preços ao Consumidor-Amplo; TCB: Taxa de Câmbio Dólar/Real; TSEC: Taxa de Juros SELIC; PIBO: Produto Interno Bruto do Agronegócio; PIBI: Produto Interno Bruto da Agricultura; PIBPC: Produto Interno Bruto da Pecuária; SBCA: Saldo da Balança Comercial do Agronegócio; IPE: Índice de Preços de Exportação do Agronegócio Brasileiro; IC: Índice de Câmbio Efetivo do Agronegócio Brasileiro; IAT: Índice de Atratividade das Exportações do Agronegócio Brasileiro; IVE: Índice de Volume de Exportações do Agronegócio Brasileiro. Células em Negrito: relações significativas ao nível de $10 \%$.

Fontes: resultados da pesquisa, elaborado pelos autores (2018).

Observa-se que cada uma das células da Tabela 3, carrega o coeficiente de correlação linear na parte superior e o respectivo p-valor na parte inferior, sinalizando o grau de associação entre as variáveis medidas par-a-par. 
A relação entre o comportamento do indicador de liquidez corrente das empresas de capital aberto do agronegócio pela variação de índices econômicos no Brasil

Conforme mencionando na seção de aspectos metodológicos, a matriz de correlação será analisada pelo Coeficiente de Correlação Linear de Pearson ( $r$ ), que segundo Johnson e Wichern (2007) podem variar entre -1 e +1 , sinalizando o sentido da correlação e a força entre os pares analisados quão mais próximos o coeficiente estiver deste número.

Ayres et. al. (2007) ainda acrescentou, que este teste de correlação é feito sob duas hipóteses. A hipótese nula é de que o $r$ é igual a zero e assim não haverá correlação entre os pares analisados. Para o $r$ diferente de zero, há de se analisar o p-valor. Em que uma correlação fraca é representada por um p-valor entre 0,05 e 0,10. Uma correlação forte apresenta p-valor entre 0,01 e 0,05. E correlações fortíssimas apresentam p-valor menor que 0,01 . As análises a seguir dos resultados da Tabela 6, estão alinhadas a estes critérios.

Analisando-se o resultado, verifica-se ser baixa a correlação linear entre o ILC e as índices econômicos. Apenas 4 dos 12 pares analisados apresentaram p-valor significativo, mas, no entanto, apenas a correlação entre o ILC e o PIB do país é classificada como forte ( $p$-valor $<0,05)$.

Assim, com um $r$ de -0,129 pode-se constatar que uma variação positiva do IC está correlacionada a um comportamento inverso do ILC das empresas do agronegócio. Na prática isto corrobora, as percepções de CEPEA (2016), Serigati (2013) e Sonaglio et al. (2016), em que explicam que a médio e em longo prazo, a desvalorização do real frente às principais moedas internacionais, faz o custo operacional do agronegócio aumentar devido à grande quantidade de insumos importados necessários à atividade. Estes resultados validam os achados de Silva et al. (2017) para as empresas listadas no setor de bens industriais e matérias básicos, em que os autores identificaram que os Indicadores de Liquidez Imediata, Seca, Corrente e Geral apresentaram comportamento inversamente proporcional a taxa de câmbio. Observa-se que na Tabela 2, a TCB não apresentou relação significativa, mas o sinal negativo indica que o sentido de todas as correlações entre liquidez e câmbio, também é inverso.

A outra correlação linear forte observada foi entre a liquidez corrente e o PIB $(r=0,1322)$. Na análise desta dinâmica, o CEPEA (2016) alertou que os impactos da taxa de câmbio e das variáveis que derivam dela, podem acelerar ou reduzir esta correlação. E isto pode ser confirmado nas duas correlações fortes obtidas para os indicadores de liquidez. Pois, mesmo o ILC se comportando negativamente ao lado da média das taxas de câmbio (IC) dos principais parceiros comerciais do país e os índices de atividade do setor estarem sofrendo reduções ao longo do período de análise, ainda existe uma pequena correlação positiva $(0,1322)$ entre o aumento do PIB do país e o aumento da sobra financeira de curto prazo (ILC) do setor. Isto indica que o consumo das famílias pode mesmo estar direcionado aos produtos deste setor no período de crise econômica (SERIGATI, 2013).

Para esta análise, ainda há de se alertar não terem sido encontrados nas revisões de literatura, estudos que analisaram a relação dos Índices Microeconômicos, dos de Atividade do Setor com o Mercado Externo, com o ILC das empresas, por isso, os achados obtidos a partir destes dois grupos são de cunho exploratório, conforme alertou Serigati (2013).

\subsection{Análise de Dados em Painel da Regressão Linear Múltipla entre o ILC e os Índices Econômicos}

Neste tópico, a atenção foi direcionada à relação de curto prazo entre ativos e passivos circulantes, pela análise da interação do Indicador de Liquidez de Corrente (ILC) dos três grupos de empresas, comparado aos três grupos de variáveis independentes do estudo (Tabelas 3, 4 e 5).

Para esta análise, recorda-se antes que, este é um indicador que evidencia a proporção de ativos circulantes existentes para cada unidade de passivos circulantes, que a empresa precisa saldar no curto prazo (MARTINS; DINIZ; MIRANDA, 2014). A partir disso, apresenta-se o primeiro painel para análise da relação entre o ILC das Empresas de Capital Aberto do Agronegócio, com a flutuação dos índices macroeconômicos entre 2010 e 2016.

Analisando-se a Tabela 13, o Teste de Chow demonstrou que o modelo de efeitos constantes foi o mais adequado para se analisar as interações entre o ILC do Grupo de Empresas Intra e as Variáveis Independentes Macroeconômicas.

Observando-se os resultados do Teste Hausman (p-valor menor ou igual a 0,005), identificou-se que o melhor modelo para análise dos Grupos de Empresas Geral e Extra, foi o de efeitos fixos. Complementarmente o Teste de Wooldridge evidenciou a existência de auto correlação ao nível de 5\% de significância e o Teste Wald retornou significância estatística para a presença de heterocedasticidade. 
Assim, a estimação do modelo de efeitos fixos para os dois grupos foi realizada para se alcançar a homocedasticidade e para se eliminar os efeitos da autocorrelação serial.

Os coeficientes apresentados das empresas do Grupo Intra, esclareceram a não significância estatística da relação entre o ILC e as variáveis macroeconômicas. Recorda-se que as empresas deste grupo conforme os critérios desta pesquisa foram aqueles que mantiveram atuação no setor do agronegócio de modo direto, e tal como alertado por Serigati (2013) o setor do agronegócio tem sentido menos a influência do contexto macroeconômico em sua atividade.

Para os Grupos Geral e Extra, as relações significantes (*) demonstraram que apenas o PIB do Brasil se relacionou com o ILC. Observou-se também que os coeficientes demonstraram que o ILC do Grupo Extra $\left(0,1421^{*}\right)$ se relacionou mais com o PIB do que o ILC do Grupo Geral $\left(0,0720^{*}\right)$, e como o Grupo Intra não evidenciou nenhuma relação, a interação verificada dentro do grupo que carrega as variáveis dependentes de todas as empresas, pode ser devida a presença das variáveis das empresas que atuam nas atividades de suporte ao agronegócio.

Tabela 3 - Coeficientes do Modelo de Indicador de Liquidez Corrente Versus Variáveis Macroeconômicas

\begin{tabular}{|c|c|c|c|c|c|c|c|c|c|}
\hline \multirow{2}{*}{ VAR } & \multicolumn{3}{|c|}{ Modelo Pooled } & \multicolumn{3}{|c|}{ Modelo de Efeitos Fixos } & \multicolumn{3}{|c|}{ Modelo de Efeitos Aleatórios } \\
\hline & Geral & Extra & Intra & Geral & Extra & Intra & Geral & Extra & Intra \\
\hline Const, & $1,0104 *$ & 0,6327 & $1,2559 *$ & $1,0104 *$ & 0,6326 & $1,2559 *$ & $1,010^{*}$ & 0,6327 & $1,2559^{*}$ \\
\hline PIB & 0,0720 & 0,1421 & 0,0264 & $0,0720 *$ & $0,1421 *$ & 0,0264 & 0,072 & $0,1421^{*}$ & 0,0264 \\
\hline IPCA & $-0,0934$ & $-0,1834$ & $-0,0350$ & $-0,0934$ & $-0,1834$ & $-0,035$ & $-0,0934$ & $-0,1834$ & $-0,035$ \\
\hline TCB & 0,2761 & 0,4898 & 0,1371 & 0,2761 & 0,4898 & 0,1371 & 0,2761 & 0,4898 & 0,1371 \\
\hline TSLIC & 0,0192 & 0,0923 & $-0,0283$ & 0,0192 & 0,0923 & $-0,0283$ & 0,0191 & 0,0923 & $-0,0283$ \\
\hline \multicolumn{10}{|c|}{ Testes para a escolha do modelo } \\
\hline \multicolumn{4}{|c|}{ Teste de Chow - Geral } & \multicolumn{3}{|c|}{$\mathrm{F}(1,225)=8,40343$} & \multicolumn{3}{|c|}{$\mathrm{p}-$ valor $=0,0041$} \\
\hline \multicolumn{4}{|c|}{ Testes de Chow - Extra } & \multicolumn{3}{|c|}{$F(1,85)=4,56863$} & \multicolumn{3}{|c|}{$\mathrm{p}-$ valor $=0,0354$} \\
\hline \multicolumn{4}{|c|}{ Teste de Chow - Intra } & \multicolumn{3}{|c|}{$F(1,134)=3,00624$} & \multicolumn{3}{|c|}{$p-$ valor $=0,0852$} \\
\hline \multicolumn{4}{|c|}{ Teste LM Breusch Pagan - Geral } & \multicolumn{3}{|c|}{$\chi^{2}(1)=348,042$} & \multicolumn{3}{|c|}{$\mathrm{p}-$ valor $=0,0000$} \\
\hline \multicolumn{4}{|c|}{ Teste LM Breusch Pagan - Extra } & \multicolumn{3}{|c|}{$\chi^{2}(1)=123,82$} & \multicolumn{3}{|c|}{$\mathrm{p}-$ valor $=0,0000$} \\
\hline \multicolumn{4}{|c|}{ Teste LM Breusch Pagan - Intra } & \multicolumn{3}{|c|}{$\chi^{2}(1)=267,134$} & \multicolumn{3}{|c|}{$\mathrm{p}-$ valor $=0,0000$} \\
\hline \multicolumn{4}{|c|}{ Teste de Hausman - Geral } & \multicolumn{3}{|c|}{$\chi^{2}(2)=12,105$} & \multicolumn{3}{|c|}{$p-$ valor $=\mathbf{0 , 0 0 2 3 5}$} \\
\hline \multicolumn{4}{|c|}{ Teste de Hausman - Extra } & \multicolumn{3}{|c|}{$\chi^{2}(2)=5,992$} & \multicolumn{3}{|c|}{$p-$ valor $=0,04998$} \\
\hline \multicolumn{4}{|c|}{ Teste de Hausman - Intra } & \multicolumn{3}{|c|}{$\chi^{2}(2)=0,274$} & \multicolumn{3}{|c|}{$\mathrm{p}-$ valor $=0,87208$} \\
\hline \multicolumn{4}{|c|}{ Teste de Wooldridge - Geral } & $\mathbf{F}(3$ & 194) $=18$ & 162 & & valor $=\mathbf{0 ,}$ & \\
\hline & Teste de Wo & dridge $-\mathrm{E}$ & & $\mathbf{F}($ & , 74) $=15$ & & & valor $=0$, & \\
\hline & Teste de Wc & ldridge $-\mathrm{I}$ & & $\mathrm{F}($ & $, 116)=2$ & & & valor $=0,0$ & \\
\hline & Teste de & ald - Ger: & & & $33)=763$ & & & valor $=\mathbf{0 ,}$ & \\
\hline & Teste de & ald - Extr & & & 13) $=241$ & & & valor $=\mathbf{0 ,}$ & \\
\hline & Teste de & ald - Intra & & & 20) $=188$ & & & valor $=0,0$ & \\
\hline
\end{tabular}

Legenda: * Significativo a 5\%; VAR: Variáveis Independentes; PIB: Produto Interno Bruto; IPCA: Índice de Preços ao Consumidor-Amplo; TCB: Taxa de Câmbio Dólar/Real; TSLIC: Taxa de Juros SELIC.

Fontes: resultados da pesquisa, elaborado pelos autores (2018).

Compara-se que este resultado corroborou os achados de Coelho (2012), que de posse de uma amostra de 141 empresas brasileiras de capital aberto (2003 a 2011), identificou que o PIB do país se correlacionou positivamente com o ILC. Demonstrando tal como nesta pesquisa, que uma elevação do PIB do Brasil, está relacionada a um aumento de 0,1421 do ILC das empresas que atuam em atividades como logística, armazenamento e transporte, e a um aumento de 0,0720 no ILC das propriedades rurais.

No entanto, alguns resultados desta pesquisa se diferiram dos achados de Coelho (2012), pois no período analisado, a autora identificou que a taxa de câmbio se correlacionou ao ILC de forma negativa, e que a taxa de juros (SELIC) se correlacionou ao ILC de maneira positiva. As diferenças destes resultados podem ser explicadas (OSAKI, 2017) pelos contextos econômicos e políticos distintos onde as duas pesquisas aconteceram. Coelho (2012) pesquisou esta interação, utilizando dados coletados num momento em que a economia do país como um todo estava em ascensão (2003 a 2011). Já neste estudo o contexto foi o oposto (CEPEA, 2016), inclusive analisando resultados de períodos (2015 e 2016) quando as 
A relação entre o comportamento do indicador de liquidez corrente das empresas de capital aberto do agronegócio pela variação de índices econômicos no Brasil

flutuações das principais variáveis de política macroeconômica do país demonstravam um contexto classificado como de crise (VASCONCELLOS; GARCIA, 2012).

Outros autores que realizaram investigação semelhante, foram Pandini et al. (2017), que estudando dados de 103 empresas dos setores de consumo cíclico e não cíclico listadas na BMF\&Bovespa, atual B3, entre 2008 e 2015, identificaram que o PIB e o ILC se relacionaram de modo positivo e significativo para o período. Este achado também corroborou o resultado desta pesquisa, e sinalizou que o incremento da folga financeira de curto prazo do setor, se relaciona ao aumento da atividade econômica do país.

Mas diferentemente, tanto dos resultados desta pesquisa, quanto da de Coelho (2012), Pandini et al. (2017) identificaram que a Taxa de Câmbio e a Taxa SELIC (juros), mantiveram relação diretamente proporcional ao ILC das empresas analisadas. Mais uma vez a diferença nos resultados pode ser devido a diversos fatores, mas elenca-se aqui o tratamento estatístico. Em suas análises Coelho (2012) utilizou a regressão linear simples, levantando a relação de cada uma das variáveis de forma independente, assim os achados da amostra que se expandiram para a população, não estavam relacionados a outras variáveis macroeconômicas.

Já Pandini et al. (2017), adotaram um modelo de correlação canônica onde todas as variáveis são comparadas ao mesmo tempo, onde "a rejeição da hipótese nula implica que ao menos a primeira correlação canônica seja estatisticamente significante, porém é possível que as demais m-1 correlações canônicas não sejam significantes" (FÁVERO et al., 2009, p. 518). Assim, mesmo que os pesquisadores tenham ganhado tempo na operacionalização estatística, pelas características do método perderam no resultado, poder de explicação das interações.

Para este e para todos os dados analisados, a proposta da análise de dados em painel balanceado executada nestes resultados, se deu na tentativa de mitigar estas fragilidades, onde dentro de um mesmo método, fosse possível separar os grupos de variáveis dependentes mais relacionadas, além de segregar os indicadores das empresas conforme sua atuação, direta ou indiretamente no agronegócio.

Ademais, acrescenta-se que a falta de relação significativa entre o ILC e o IPCA e o ILC e a Taxa SELIC, podem ser explicadas pela atuação do agronegócio se dar "numa perspectiva de longo prazo, mantendo o contínuo empenho na busca de produtividade e eficiência, o que tem garantido um crescimento sustentável ao longo de décadas, sem pressão importante sobre os seus preços relativos - e, portanto, sobre a inflação - no mercado interno" (BARROS, 2017, p. 1).

Assim, ancorado pela literatura empírica (COELHO, 2012; PANDINI et al., 2017), pode-se afirmar que a relação entre o ILC e o PIB do país a partir dos coeficientes observados nesta e nas pesquisas correlatas, é significativo e positivo, logo o aumento da atividade econômica nacional, se relacionou ao aumento do Indicador de Liquidez Corrente das Empresas do Agronegócio.

Seguindo os mesmos pressupostos estatísticos anteriores, nas próximas duas Tabelas (4 e 5), foram analisados os resultados entre o ILC e as variáveis independentes estudadas de modo exploratório nesta pesquisa.

Pelos dados da Tabela 4, o Teste de Chow demonstrou que o modelo de efeitos constantes foi o mais adequado para se analisar as interações entre o ILC do Grupo de Empresas Intra e as variáveis microeconômicas específicas do setor.

Os resultados do Teste Hausman (p-valor menor ou igual a 0,005) explicaram que o modelo de efeitos fixos foi o mais adequado para se analisar as interações das empresas do Grupo Extra, com Teste Wooldridge e Teste Wald indicando a necessidade de estimação pelo modelo de efeitos fixos, todos ao nível de 5\% de significância.

E para a análise dos dados a partir das Empresas do Grupo Geral, verificou-se que o melhor modelo de análise é o de efeitos aleatórios. Observou-se também que para as Empresas do Grupo Intra, os coeficientes não indicaram relação significativa entre seus ILC e as variáveis independentes. Logo, para o período analisado o contexto microeconômico do setor, não se relacionou com a interação entre ativos e passivos de curto prazo para as empresas que atuam dentro da cadeia do agronegócio.

Nos estudos correlatos utilizados nas discussões dos resultados da Tabela 3, observou-se que todas as evidências foram levantadas a partir de variáveis macroeconômicas. Neles, mostrou-se uma relação positiva entre o PIB do país e o ILC, corroborado pelos resultados desta pesquisa.

A partir disso, recorda-se (ADENLE et al., 2017) que quando a atividade econômica do país é positiva, que há um aumento geral da capacidade de consumo da sociedade, e isto impulsionaria também todos os setores da economia. Mas no caso do agronegócio, o movimento foi o inverso, pois o 
desenvolvimento do país acabou por alavancar a demanda da sociedade por produtos de maior valor agregado. "Ou seja, um aumento de $1 \%$ na renda nacional gera um aumento menor na demanda por produtos agrícolas do que por produtos industriais ou serviços" (SERIGATI, 2013, p. 16).

Tabela 4 - Coeficientes do Modelo de Indicador de Liquidez Corrente Versus Variáveis Microeconômicas

\begin{tabular}{|c|c|c|c|c|c|c|c|c|c|}
\hline \multirow{2}{*}{ VAR } & \multicolumn{3}{|c|}{ Modelo Pooled } & \multicolumn{3}{|c|}{ Modelo de Efeitos Fixos } & \multicolumn{3}{|c|}{ Modelo de Efeitos Aleatórios } \\
\hline & Geral & Extra & Intra & Geral & Extra & Intra & Geral & Extra & Intra \\
\hline Const, & $1,3663 *$ & $1,3180 *$ & $1,3971 *$ & $1,3663 *$ & $1,3180 *$ & $1,3977^{*}$ & $1,3663 *$ & $1,3180 *$ & $1,3977 *$ \\
\hline P-AGRO & $-0,4572$ & $-0,6922$ & $-0,3045$ & $-0,4572 *$ & $-0,6922 *$ & $-0,3045^{*}$ & $-0,4572 *$ & $-0,6922 *$ & $-0,3045^{*}$ \\
\hline P-AGRI & 0,3087 & 0,487 & 0,1928 & $0,3087 *$ & $0,4870 *$ & $0,1928 *$ & $0,3087 *$ & $0,4870^{*}$ & $0,1928 *$ \\
\hline P-PEC & 0,1484 & 0,2295 & 0,0957 & $0,1484^{*}$ & $0,2295 *$ & $0,0957 *$ & $0,1484 *$ & $0,2295^{*}$ & $0,0957 *$ \\
\hline SBC & $0,0181 *$ & 0,0283 & 0,0115 & $0,0181 *$ & $\mathbf{0 , 0 2 8 3 *}$ & $0,0115^{*}$ & 0,0181* & $0,0283^{*}$ & $0,0115^{*}$ \\
\hline \multicolumn{10}{|c|}{ Testes para a escolha do modelo } \\
\hline \multicolumn{4}{|c|}{ Teste de Chow - Geral } & \multicolumn{3}{|c|}{$\mathrm{F}(1,225)=8,60484$} & \multicolumn{3}{|c|}{$\mathrm{p}-$ valor $=0,0037$} \\
\hline \multicolumn{4}{|c|}{ Testes de Chow - Extra } & \multicolumn{3}{|c|}{$F(1,85)=4,87278$} & \multicolumn{3}{|c|}{$\mathrm{p}-$ valor $=0,0300$} \\
\hline \multicolumn{4}{|c|}{ Teste de Chow - Intra } & \multicolumn{3}{|c|}{$F(1,134)=3,00872$} & \multicolumn{3}{|c|}{$p-$ valor $=0,0851$} \\
\hline \multicolumn{4}{|c|}{ Teste LM Breusch Pagan - Geral } & \multicolumn{3}{|c|}{$\chi^{2}(1)=346,613$} & \multicolumn{3}{|c|}{$p-$ valor $=0,0000$} \\
\hline \multicolumn{4}{|c|}{ Teste LM Breusch Pagan - Extra } & \multicolumn{3}{|c|}{$\chi^{2}(1)=122,892$} & \multicolumn{3}{|c|}{$\mathrm{p}-$ valor $=0,0000$} \\
\hline \multicolumn{4}{|c|}{ Teste LM Breusch Pagan - Intra } & \multicolumn{3}{|c|}{$\chi^{2}(1)=266,111$} & \multicolumn{3}{|c|}{$\mathrm{p}-$ valor $=0,0000$} \\
\hline \multicolumn{4}{|c|}{ Teste de Hausman - Geral } & \multicolumn{3}{|c|}{$\chi^{2}(2)=4,732$} & \multicolumn{3}{|c|}{$\mathrm{p}-$ valor $=0,09384$} \\
\hline \multicolumn{4}{|c|}{ Teste de Hausman - Extra } & \multicolumn{3}{|c|}{$\chi^{2}(2)=6,532$} & \multicolumn{3}{|c|}{$p-$ valor $=0,03816$} \\
\hline \multicolumn{4}{|c|}{ Teste de Hausman - Intra } & \multicolumn{3}{|c|}{$\chi^{2}(2)=0,272$} & \multicolumn{3}{|c|}{$\mathrm{p}-$ valor $=0,87281$} \\
\hline \multicolumn{4}{|c|}{ Teste de Wooldridge - Geral } & $\mathrm{F}($ & 194) $=18$ & 955 & & valor $=0,0$ & \\
\hline Te: & te de Wool & ridge - Ex & & & , 74) $=15$ & & & valor $=\mathbf{0 , 0}$ & \\
\hline & ste de Woo & Iridge - Int & & $\mathrm{F}($ & $116)=28$ & 884 & & valor $=0,0$ & \\
\hline & Teste de W & ld - Geral & & & $33)=150$ & & & valor $=0,0$ & \\
\hline & Teste de W & ld - Extra & & & 13) $=400$, & & & valor $=0,0$ & \\
\hline & Teste de $\mathrm{K}$ & ld - Intra & & & $20)=3710$ & & & valor $=0,0$ & \\
\hline
\end{tabular}

Legenda: * Significativo a 5\%; VAR: Variáveis Independentes; P-AGRO: Produto Interno Bruto do Agronegócio; PIB-AGRI: Produto Interno Bruto da Agricultura; PIB-PEC: Produto Interno Bruto da Pecuária; SBC-AGRO: Saldo da Balança Comercial do Agronegócio.

Fontes: resultados da pesquisa, elaborado pelos autores (2018).

As sugestões teóricas anteriores dão suporte aos resultados encontrados a partir dos coeficientes entre o PIB do Agronegócio e o ILC das Empresas do Grupo Geral $(-0,4572)$ e do Grupo Extra $(-0,6922)$. Na Tabela 3 a relação do ILC com a atividade econômica do país foi positiva, já na Tabela 4, observou-se uma relação inversa entre a atividade econômica do setor e o ILC no período analisado. Complementarmente, recorda-se pelos resultados das estatísticas descritivas, que tanto o PIB do país, quanto o do setor, experimentaram reduções em seus níveis de atividade geral entre 2010 e 2016, com uma queda maior em escala nacional. Mas mesmo este contexto de queda na atividade econômica, parece não ter sido tão decisivo para o nível de ILC das empresas analisadas, conforme a Figura 3.

Figura 3 - Comportamento dos Valores Máximos, Médios e Mínimos do ILC

Comportamento dos Valores Máximos, Médios e Mínimos do ILC

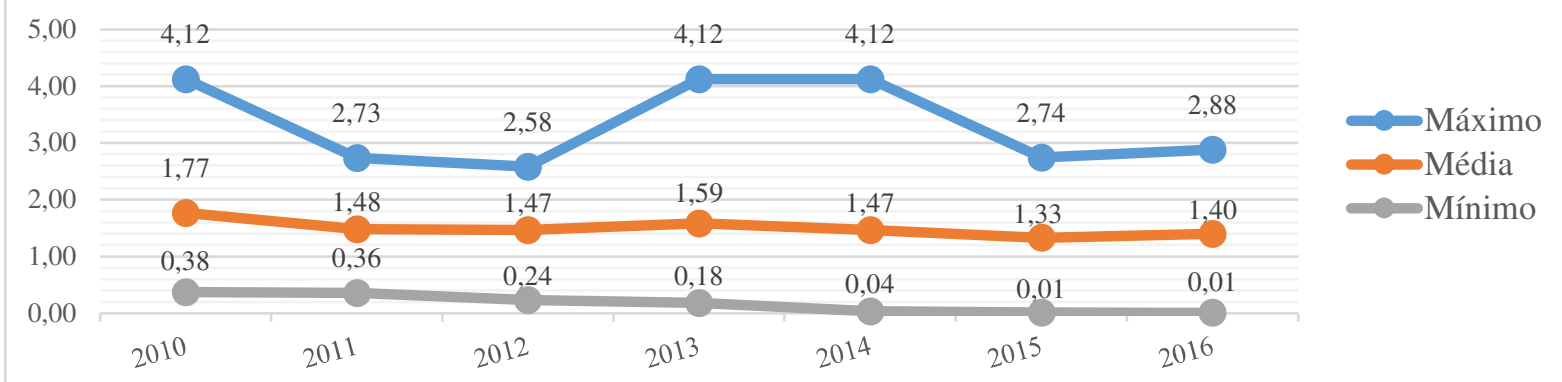

Fonte: Elaborado pelos autores, com base nos resultados da pesquisa (2018). 
A relação entre o comportamento do indicador de liquidez corrente das empresas de capital aberto do agronegócio pela variação de índices econômicos no Brasil

Observa-se na Figura 3, que mesmo num contexto econômico desfavorável o agronegócio ainda apresentou um ILC que na média sempre evidenciou uma folga financeira de mais de trinta centavos. Para o indicador, o contexto geral também foi de queda, mas como visto nas estatísticas descritivas a partir de 2014, os indicadores relacionados ao PIB do Agronegócio demonstraram um crescimento mesmo num período de crise no país.

Estes comportamentos corroboraram a literatura (SONAGLIO, 2016) sobre como o agronegócio se comporta como sustentáculo da atividade econômica em países emergentes e confirmaram a relação negativa e significativa encontrada entre o ILC e o PIB do setor.

Outro resultado observado na Tabela 4 , foi a relação positiva e significativa entre o Saldo da Balança Comercial do Agronegócio (SBC) e o ILC das Empresas dos Grupos Geral $(0,0181)$ e Extra $(0,0283)$. Ou seja, na medida em que o resíduo entre o que os participantes da cadeia produtiva do agronegócio pagam ao importar, e os valores que eles recebem no momento da exportação (FIESP, 2017) aumentam, o ILC das empresas do setor também aumenta.

Por isso, Segundo Serigati (2013, p. 16), "em alguns países, a agricultura é o setor que mais contribui para o saldo de transações correntes (o saldo das importações e exportações de bens e serviços)". E no caso brasileiro, esta relação tende a ganhar ainda mais força ao longo do tempo, pois as empresas do setor estão sujeitas tanto à variação do preço das commodities que exportam, quanto do preço/custo dos insumos que utilizam para operacionalizar sua produção. Esta dinâmica pode ser visualizada no conforme o Quadro 7.

Quadro 7 - Indicadores Setoriais do Agronegócio
\begin{tabular}{|l|l|l|l|l|}
\hline Indicadores & 2013 & 2014 & 2015 & 2016 \\
\hline PIB percentual do Agronegócio no PIB do país & 20,24 & 20,56 & 21,46 & 22,8 \\
\hline Exportações percentuais da Agropecuária & 35,80 & 36,71 & 38,96 & 42,20 \\
\hline Exportações percentuais do Agronegócio & 41,30 & 42,98 & 46,16 & 49,55 \\
\hline
\end{tabular}

Fonte: adaptado de Ministério da Agricultura, Pecuária e Abastecimento (MAPA) (2016).

Nele todos os cenários demonstrados pelo MAPA (2016), evidenciaram que a participação do setor na economia tende a aumentar, com destaque principal para as variáveis relacionadas ao mercado externo. As exportações do agronegócio por exemplo, absorveram mais de $8 \%$ das exportações do país em quatro anos. Assim, a relação positiva e significativa entre o ILC e o Saldo da Balança Comercial se justificou neste cenário.

Complementando a análise do ILC pela relação das empresas com o mercado externo, também foram estudados os indicadores de atividade do setor (Tabela 15), calculados e disponibilizados por CEPEA (2016). Assim, observou-se que na Tabela 5, foi baixa a relação de significância entre as variáveis de atividade do setor com o mercado externo e o ILC das empresas da amostra. E nela, apenas o Índice de Câmbio Efetivo do Agronegócio apresentou coeficiente significativo, indicando que um aumento da taxa de câmbio dos 10 parceiros econômicos mais importantes do agronegócio brasileiro conserva uma pequena relação negativa e significativa com o ILC das Empresas dos Grupos Extra $(-0,0060)$.

Este resultado pode ser equiparado a um dos achados de Silva et al. (2017) que pesquisaram também entre 2010 e 2016, a relação do ILC das empresas listadas no setor de bens industriais, ou Grupo Extra nesta pesquisa, e encontraram pelo método da Matriz de Correlação Linear uma relação inversa entre o ILC e a Taxa de Câmbio, conforme resultado semelhante na Tabela 5.

Em resumo, neste artigo constatou-se que pelos resultados observados na análise da interação entre o ILC e as variáveis independentes, que um incremento da atividade econômica do país (PIB), se manteve relacionado positivamente a um aumento da liquidez de curto prazo do agronegócio, acrescentando que o Saldo da Balança Comercial do setor quando positivo, também impulsionou o aumento do ILC.

No comportamento oposto, o ILC se relacionou de modo negativo ao PIB calculado pelas atividades correntes do setor, mas mesmo assim o setor apresentou no período, de acordo com Martins, Diniz e Miranda (2014), uma folga financeira favorável.

Na relação com o mercado externo, o ILC do setor mostrou que a desvalorização do real frente às moedas dos parceiros comerciais do setor, não foi benéfica para a situação financeira de sua liquidez de curto prazo. 
Tabela 5 - Coeficientes do Modelo de Indicador de Liquidez Corrente Versus Índices de Atividade do Setor

\begin{tabular}{|c|c|c|c|c|c|c|c|c|c|}
\hline \multirow{2}{*}{ VAR } & \multicolumn{3}{|c|}{ Modelo Pooled } & \multicolumn{3}{|c|}{ Modelo de Efeitos Fixos } & \multicolumn{3}{|c|}{ Modelo de Efeitos Aleatórios } \\
\hline & Geral & Extra & Intra & Geral & Extra & Intra & Geral & Extra & Intra \\
\hline Const, & $1,3776^{*}$ & $1,3774 *$ & $1,3777 *$ & $1,3776^{*}$ & $1,3774 *$ & $1,3777 *$ & $1,3776 *$ & $1,3774 *$ & $1,3777^{*}$ \\
\hline IPE & 0,0033 & 0,0033 & $\mathbf{0 , 0 0 3 5}$ & 0,0033 & $\mathbf{0 , 0 0 3 3}$ & 0,0035 & $\mathbf{0 , 0 0 3 3}$ & 0,0033 & 0,0035 \\
\hline IC & $-0,0021$ & $-0,0060$ & 0,0003 & $-0,0021$ & $-0,0060 *$ & 0,0003 & $-0,0021$ & $-0,0060 *$ & 0,0003 \\
\hline IAT & 0,0004 & 0,0022 & $-\mathbf{0 , 0 0 0 7}$ & 0,0004 & 0,0022 & $-0,0007$ & 0,0004 & 0,0022 & $-0,0007$ \\
\hline IVE & 0,0069 & 0,0084 & 0,006 & 0,0069 & 0,0084 & 0,006 & 0,0069 & 0,0084 & 0,0060 \\
\hline \multicolumn{10}{|c|}{ estes para a escolha do modelo } \\
\hline \multicolumn{4}{|c|}{ Teste de Chow - Geral } & \multicolumn{3}{|c|}{$\mathrm{F}(1,225)=8,65977$} & \multicolumn{3}{|c|}{$\mathrm{p}-$ valor $=0,0036$} \\
\hline \multicolumn{4}{|c|}{ Testes de Chow - Extra } & \multicolumn{3}{|c|}{$\mathrm{F}(1,85)=4,73119$} & \multicolumn{3}{|c|}{$\mathrm{p}-$ valor $=0,0324$} \\
\hline \multicolumn{4}{|c|}{ Teste de Chow - Intra } & \multicolumn{3}{|c|}{$F(1,134)=3,19431$} & \multicolumn{3}{|c|}{$p-$ valor $=0,0762$} \\
\hline \multicolumn{4}{|c|}{ Teste LM Breusch Pagan - Geral } & \multicolumn{3}{|c|}{$\chi^{2}(1)=342,493$} & \multicolumn{3}{|c|}{$p-$ valor $=0,0000$} \\
\hline \multicolumn{4}{|c|}{ Teste LM Breusch Pagan - Extra } & \multicolumn{3}{|c|}{$\chi^{2}(1)=119,856$} & \multicolumn{3}{|c|}{$\mathrm{p}-$ valor $=0,0000$} \\
\hline \multicolumn{4}{|c|}{ Teste LM Breusch Pagan - Intra } & \multicolumn{3}{|c|}{$\chi^{2}(1)=263,211$} & \multicolumn{3}{|c|}{$\mathrm{p}-$ valor $=0,0000$} \\
\hline \multicolumn{4}{|c|}{ Teste de Hausman - Geral } & \multicolumn{3}{|c|}{$\chi^{2}(2)=5,392$} & \multicolumn{3}{|c|}{$\mathrm{p}-$ valor $=0,06746$} \\
\hline \multicolumn{4}{|c|}{ Teste de Hausman - Extra } & \multicolumn{3}{|c|}{$\chi^{2}(2)=7,477$} & \multicolumn{3}{|c|}{$p-$ valor $=0,02378$} \\
\hline \multicolumn{4}{|c|}{ Teste de Hausman - Intra } & \multicolumn{3}{|c|}{$\chi^{2}(2)=0,259$} & \multicolumn{3}{|c|}{$\mathrm{p}-$ valor $=0,87841$} \\
\hline \multicolumn{4}{|c|}{ Teste de Wooldridge - Geral } & & 194) $=17$ & & & valor $=0,0$ & \\
\hline & Teste de $\mathrm{Y}$ & dridge - & & & $2,74)=15$ & & & valor $=\mathbf{0 , 0}$ & \\
\hline & Teste de & ldridge - & & & 116) $=28$ & & & valor $=0,0$ & \\
\hline & Teste d & ald - Ger & & & $(33)=547$ & & & valor $=0,0$ & \\
\hline & Teste d & ald - Ex & & & $(13)=618$, & & & alor $=\mathbf{0 , 0}$ & \\
\hline & Teste & Vald - Int & & & $(20)=123$ & & & valor $=0,0$ & \\
\hline
\end{tabular}

Legenda: * Significativo a 5\%; VAR: Variáveis Independentes; IPE: Índice de Preços de Exportação do Agronegócio Brasileiro; IC: Índice de Câmbio Efetivo do Agronegócio Brasileiro; IAT: Índice de Atratividade das Exportações do Agronegócio Brasileiro; IVE: Índice de Volume de Exportações do Agronegócio Brasileiro.

Fontes: resultados da pesquisa, elaborado pelo autor (2017).

\section{Considerações Finais}

Recorda-se que os resultados analisados neste artigo, foram discutidos para responder a problemática deste estudo, sobre qual foi a relação entre a flutuação de índices econômicos do país e o comportamento do indicador de liquidez corrente das empresas de capital aberto do setor do agronegócio brasileiro.

Assim, considera-se que através da pesquisa desenvolvida pela operacionalização dos métodos estatísticos (Descritivos, Matriz de Correlação e Análise de Dados em Painel), que o objetivo geral da pesquisa foi atingido e neste sentido, também foi respondido o problema de pesquisa através dos resultados que foram apresentados e discutidos na seção anterior.

Sobre estes resultados, alguns foram mais relevantes, pois corroboraram e ou refutaram resultados já apresentados em pesquisas anteriores. Assim, concluiu-se que pela análise do Coeficiente de Correlação Linear de Pearson $(r)$, que para os índices macroeconômicos, o Indicador de Liquidez Corrente apresentou uma correlação forte (p-valor $<0,05$ ) ao PIB do país. Evidenciando que o incremento positivo da riqueza produzida internamente no país, colaborou para que a situação de curto prazo das empresas do agronegócio experimentasse o que Serigati (2013) explicou como folga financeira. Também foi encontrado na análise deste coeficiente um $r$ de $-0,129$, para a análise entre a Liquidez Corrente e o Índice de Câmbio do Agronegócio (IC). Este resultado justifica as evidências de CEPEA (2016), Serigati (2013) e Sonaglio et al. (2016), quando de modo semelhante afirmaram que a médio e em longo prazo, a desvalorização do real frente às principais moedas internacionais, faz o custo operacional do agronegócio aumentar devido à grande quantidade de insumos importados inerentes a este tipo de atividade.

Já pela a Análise de Dados em Painel, o contexto macroeconômico, identificou uma relação direta entre o PIB do país e a folga financeira evidenciada pelo indicador. Este foi um resultado relevante, pois corroborou resultados semelhantes encontrados na literatura anteriormente como o de Coelho (2012). E com base nos testes estatísticos realizados, pelo Modelo de Efeitos Fixos, as Empresas do Grupo Extra, 
A relação entre o comportamento do indicador de liquidez corrente das empresas de capital aberto do agronegócio pela variação de índices econômicos no Brasil

absorveram a maior parte da influência do PIB do país na Liquidez Corrente. Verificou-se também que o coeficiente estatisticamente significativo do Modelo de Efeitos Fixos para estas empresas foi de 0,1421*, enquanto que o coeficiente estatisticamente significativo do mesmo modelo para as empresas do Grupo Geral foi de 0,0720*. Ou seja, a variação positiva do PIB do país gerou um incremento maior de sobra financeira de curto prazo para as empresas que atuam da porteira para fora do agronegócio, pois as do setor direcionaram estas sobras diretamente para a atividade na empresa.

Já em nível microeconômico, a unanimidade das relações entre o ILC e as variáveis independentes indicou que a atividade econômica do setor se relacionou significativamente com a sobra financeira de curto prazo de suas empresas. E pela análise do coeficiente entre o PIB do Agronegócio e o Indicador de Liquidez Corrente, negativos tanto para as empresas do Grupo Geral (-0,6922*), quanto para as empresas do Grupo Extra $(\mathbf{0 , 4 5 7 2}$ ), que a correspondência e validação teórica foram corretas. Pois, pelos achados de Serigati (2013) os incrementos de riqueza do setor, nesta pesquisa expressos pelo aumento do PIBAGRO, potencializaram a utilização dos recursos de curto prazo da empresa em sua atividade produtiva, constatando-se que quanto maior a geração de riqueza no agronegócio, menor será a disponibilidade de recursos no curto prazo, pois elas serão imediatamente realocadas à operação da empresa.

Com estes principais resultados evidenciados, tendo alcançado o objetivo geral e respondido o problema de pesquisa a partir de todas as interações levantadas neste artigo, às sugestões de pesquisas futuras nesta área de comparação entre indicadores econômico-financeiros e índices econômicos, é pelo aprofundamento do entendimento da composição de cada indicador econômicofinanceiro analisado, antes de se construir as interações evidenciadas a partir dele.

Pois, conforme alertado no referencial teórico, no momento da apresentação das particularidades de cada indicador, as ponderações apresentadas (ASSAF NETO, 2006; IUDÍCIBUS, 2009; MARION, 2009; MARTINS; DINIZ; MIRANDA, 2014) indicaram que os horizontes temporais de vencimento das contas que os compõe, podem produzir interpretações enviesadas, por isto, as pesquisas futuras que ampliem estes indicadores a partir de suas composições são necessárias.

Com tudo, a última sugestão para os próximos estudos, é conduzir investigações semelhantes utilizando métodos estatísticos diferentes, ou ainda pela própria análise qualitativa destas interações. Pois como exposto na seção de resultados, algumas relações que se desenharam correspondentes, não foram estatisticamente significantes quando analisadas pela Análise de Regressão Múltipla através da Técnica de Análise de Dados em Painel. Por isso, esta sugestão se dá no sentido de que alguma técnica de análise de regressão não linear, possa identificar como as proporcionalidades destas relações acontecem no contexto estatístico, que o método da regressão linear múltipla não conseguiu identificar.

Como contribuições para a teoria e para as práticas acadêmica e empresarial, este estudo abordou significativamente o contexto dos indicadores contábeis, provando que a partir das interações estatísticas dos Modelos de Efeitos Fixos, Constantes e Aleatórios, operacionalizados pela técnica da Análise de Dados em Painel, que é possível monitorar como os índices econômicos de um país ou setor, se relacionam com os indicadores contábeis das empresas, sendo um grande destaque científico deste estudo, além dos resultados estatisticamente significantes encontrados, o método operacionalizado para provar as relações que se pretendeu.

Por todo o exposto, registra-se que este artigo não esgotou (e nem pretendeu) a análise das relações propostas, mas atuou identificando como aconteceu a relação entre a flutuação de índices econômicos do país, com o comportamento do Indicador de Liquidez Corrente das empresas de capital aberto do agronegócio, classificadas com base nas readequações propostas por CEPEA (2014) e operacionalizado pela aplicação da técnica da Análise de Dados em Painel, com observações coletados entre 2010 e 2016.

\section{Referências}

ADENLE, Ademola A.; MANNING, Louise; AZADI, Hossein. Agribusiness innovation: A pathway to sustainable economic growth in Africa. Trends in Food Science \& Technology, v. 59, p. 88-104, 2017. https://doi.org/10.1016/j.tifs.2016.11.008

\section{AGGARWAL, Raj. Exchange rates and stock prices: A study of the US capital markets under}

floating exchange rates. 2003. Disponível em: <http://www.sid.ir/En/Journal/ViewPaper.aspx?ID=363021>. Acesso em: dezembro de 2016. 
ALMEIDA, Katia de; MACEDO, Marcelo Alvaro da Silva. Analise do Desempenho Contábil-Financeiro no Agronegócio Brasileiro: Aplicando DEA ao Setor Agroindustrial nos anos de 2006 e 2007. Pensar Contábil, v. 12, n. 48, 2010.

ASSAF NETO, A. Estrutura e Análise de Balanços: um enfoque econômico-financeiro. São Paulo: Atlas. 2006.

ASSAF NETO, Alexandre. Finanças Corporativas e Valor. São Paulo: Atlas, 2003.

AYRES, Manuel; AYRES JÚNIOR, Manuel; AYRES, Daniel Lima; SANTOS, Alex Santos dos. BioEstat 5.3: aplicações estatísticas nas áreas das ciências biológicas e médicas. Belém: MCT; IDSM; CNPq, 2007. 364 p. il. Acompanha CD-ROM. .

BANCO CENTRAL DO BRASIL. Taxa SELIC - Conceito. Banco Central do Brasil, 2017. Disponível em: <http://www.bcb.gov.br/htms/selic/conceito_taxaselic.asp>. Acesso em: janeiro de 2017.

BASTOS, DOUGLAS DIAS; TOSHIRO NAKAMURA, WILSON; CRUZ BASSO, LEONARDO FERNANDO. Determinantes da estrutura de capital das companhias abertas na América Latina: um estudo empírico considerando fatores macroeconômicos e institucionais. RAM. Revista de Administração Mackenzie, v. 10, n. 6, 2009. https://doi.org/10.1590/S1678-69712009000600005

BEAVER, William H. Financial ratios as predictors of failure. Journal of Accounting Research, p. 71111, 1966. DOI: https://doi.org/10.2307/2490171

BRASIL. BACEN. Banco Central do Brasil. Sistema Gerenciador de Séries Temporais: Expectativas do Mercado. 2017. Disponível em:

<https://www3.bcb.gov.br/expectativas/publico/consulta/serieestatisticas〉. Acesso em: janeiro de 2017.

BRASIL. CEPEA/CNA. PIB do Agronegócio Brasileiro. 2016. Disponível em:

<http://www.cepea.esalq.usp.br/br/pib-do-agronegocio-brasileiro.aspx>. Acesso em: abril de 2017.

BRASIL. Cepea. Cepea/esalq/usp. METODOLOGIA ÍNDICE DE EXPORTAÇÃO DO

AGRONEGÓCIO: IPE-AGRO/CEPEA - Índice de Preços de Exportação do Agronegócio Brasileiro.

IC-AGRO/CEPEA - Índice de Câmbio Efetivo do Agronegócio Brasileiro. IAT-AGRO/CEPEA - Índice de Atratividade das Exportações do Agronegócio. IVE-AGRO/CEPEA - Índice de Volume de Exportações do Agronegócio. 2017. Disponível em:

<http://www.cepea.esalq.usp.br/br/metodologia/metodologia-1.aspx>. Acesso em: janeiro de 2017.

BRASIL. Constituição (2014). Extrato de Inexigibilidade de Licitação no O N 27/2014 - UASG 154043, de 27 de junho de 2014. Serviço renovação de sofware Total de Itens Licitados: 00001. Fundamento Legal: Art. $25^{\circ}$, Inciso I da Lei no 8.666 de 21/06/1993.. J. Extrato de Inexigibilidade de Licitação No 27/2014 - Uasg 154043: Extrato de Licitação Serviço Público Federal. 1. ed. v. 1, n. 1, Seção 1, p. 220 220. Disponível em: <http://www.faced.ufu.br/sites/faced.ufu.br/files/DOU 30-06-14 H113 ESTES, H114 FACOM, H115 FACED, H 116 FAGEN.pdf>. Acesso em: março de 2017.

BRASIL. DEAGRO/FIESP. Federação das Indústrias do Estado de São Paulo. Balança Comercial Brasileira do Agronegócio: Boletim Informativo. 2017. Disponível em:

$<$ http://www.fiesp.com.br/indices-pesquisas-e-publicacoes/balanca-comercial/>. Acesso em: janeiro de 2017.

BRASIL. IBGE. Instituto Brasileiro de Geografia e Estatística. Sistema Nacional de Índices de Preços ao Consumidor: Índice Nacional de Preços ao Consumidor Amplo - IPCA e Índice Nacional de Preços ao Consumidor - INPC. 2017. Disponível em: 
A relação entre o comportamento do indicador de liquidez corrente das empresas de capital aberto do agronegócio pela variação de índices econômicos no Brasil

<http://www.ibge.gov.br/home/estatistica/indicadores/precos/inpc_ipca/defaultinpc.shtm>. Acesso em: janeiro de 2017.

BRASIL. Lei nº 6.404, de 15 de dezembro de 1976. Dispõe sobre as Sociedades por Ações. Disponível em: <http://www.planalto.gov.br/ccivil_03/Leis/L6404consol.htm.> Acesso em: janeiro de 2017.

BRASIL. Lei n. ${ }^{\circ} 11.638$, de 28 de dezembro de 2007. Altera e revogam dispositivos da Lei n. $^{\circ} 6.404$, de 15 de dezembro de 1976 , e da Lei n. ${ }^{\circ} 6.385$, de 7 de dezembro de 1976 , e estende às sociedades de grande porte disposições relativas à elaboração e divulgação de demonstrações financeiras. Disponível em: <http://www.planalto.gov.br/ccivil/_Ato2007-2010/2007/Lei/L11638.htm>. Acesso em: janeiro de 2017.

BATALHA, Mário Otávio. (Coord.) Gestão Agroindustrial. 3. ed. São Paulo: Atlas, 2007.

BARROS, A. J. S.; LEHFELD, N. A. S. Fundamentos de metodologia científica.

3.ed. São Paulo: Prentice-Hall, 2007.

BARROS, Geraldo Sant'ana De Camargo (São Paulo). Professor Titular e Coordenador do Centro de Estudos Avançados em Economia Aplicada (CEPEA) da ESALQ/USP. POLÍTICAS, POLÍTICOS E O AGRONEGÓCIO NO BRASIL. 2005. Disponível em:

<http://www.cepea.esalq.usp.br/br/documentos/texto/politicas-politicos-e-o-agronegocio-no-brasil.aspx>. Acesso em: janeiro de 2017.

BARROS, Geraldo Sant'ana De Camargo. O Agronegócio e a Queda da Inflação. 2017. Disponível em: $<$ https://www.cepea.esalq.usp.br/br/opiniao-cepea/agronegocio-e-a-queda-da-inflacao.aspx >. Acesso em: dezembro de 2017.

BARROS, Geraldo Sant' ana De Camargo. O Agronegócio e as Crises Interna e Externa: Desafios e Oportunidades. 2017. Disponível em: <https://www.cepea.esalq.usp.br/br/opiniao-cepea/o-agronegocio-eas-crises-interna-e-externa-desafios-e-oportunidades.aspx>. Acesso em: dezembro de 2017.

BARROS, Geraldo Sant' ana De Camargo; ADAMI., Andréia Cristina De Oliveira. Exportação do agronegócio bate novo recorde, mesmo com queda de preço. Índices exportação do agronegócio, São paulo, p. 1-9, dez. 2012. Disponível em:

<http://www.cepea.esalq.usp.br/upload/kceditor/files/cepea_exportagro_2012.doc>.Acesso em: janeiro de 2017.

BARROS, Geraldo Sant' ana De Camargo; ADAMI., Andréia Cristina De Oliveira. Aumento Recorde dos Preços Garante Faturamento do Agronegócio em 2011. Índices exportação do agronegócio, São paulo, p. 1-9, dez. 2011. Disponível em:

<http://www.cepea.esalq.usp.br/upload/kceditor/files/Cepea_ExportAgro_2011.doc>.Acesso em: janeiro de 2017.

BARROS, Geraldo Sant' ana De Camargo; ADAMI, Andréia Cristina De Oliveira; COUTO, Thierry Fuger Reis. Com vendas e preços menores, faturamento cai em 2016. Índices exportação do agronegócio, São Paulo, p. 1-9, dez. 2016. Disponível em:

<https://www.cepea.esalq.usp.br/upload/kceditor/files/2016.pdf>.Acesso em: janeiro de 2017.

BARROS, Geraldo Sant'ana De Camargo; ADAMI, Andréia Cristina De Oliveira; FRICKS,

Luana. Câmbio ajuda, volume exportado bate recorde, mas faturamento em dólar volta a cair em

2015. Índices exportação do agronegócio, São Paulo, p. 1-9, dez. 2015. Disponível em:

<http://www.cepea.esalq.usp.br/upload/kceditor/files/cepea_exportagro_2015.docx >.Acesso em: janeiro de 2017.

BARROS, Geraldo Sant' ana De Camargo; ADAMI, Andréia Cristina De Oliveira; ZANDONÁ, Nicole 
Ferro. Embarques dos produtos do agronegócio recuam em 2014. Índices exportação do agronegócio, São Paulo, p. 1-9, dez. 2014. Disponível em:

<http://www.cepea.esalq.usp.br/upload/kceditor/files/cepea_exportagro_2014.doc>.Acesso em: janeiro de 2017.

BARROS, Geraldo Sant'ana De Camargo; ADAMI, Andréia Cristina De Oliveira; ZANDONÁ, Nicole Ferro. Faturamento e volume exportado do agronegócio brasileiro são recordes em 2013. Índices exportação do agronegócio, São paulo, p. 1-9, dez. 2013. Disponível em:

<http://www.cepea.esalq.usp.br/upload/kceditor/files/cepea_exportagro_2013.doc>.Acesso em: janeiro de 2017.

BERNARDELLI, L. V. BERNARDELLI, A. G. Análise sobre a Relação do Mercado Acionário com as Variáveis Macroeconômicas no Período de 2004 a 2014. Revista Evidenciação Contábil \& Finanças, [s.l.], v. 4, n. 1, p.4-17, 27 abr. 2016.

BM\&FBOVESPA; - BOLSA DE MERCADORIAS E FUTURO E BOLSA DE VALORES DE SÃO PAULO (São Paulo) (Comp.). Empresas Listadas. 2016. Disponível em:

<http://www.bmfbovespa.com.br/pt_br/produtos/listados-a-vista-e-derivativos/renda-variavel/empresaslistadas.htm>. Acesso em: dezembro de 2016.

B3; BRASIL, BOLSA, BALCÃO S.A. (São Paulo) (Comp.). Empresas Listadas. 2017. Disponível em: $<$ http://www.b3.com.br/pt_br/>. Acesso em: maio de 2017.

CARVALHO, André Roncaglia de. A persistência da indexação no Brasil pós-Real. Brazilian Journal of Political Economy/Revista de Economia Política, v. 34, n. 2, 2014. DOI: 10.1590/S0101-

31572014000200006

CEPEA-ESALQ (São Paulo). PIB DO AGRONEGóCIO BRASILEIRO: Comentários de Agosto de 2016. 2016. Disponível em: 〈http://www.cepea.esalq.usp.br/br/pib-do-agronegocio-brasileiro.aspx>. Acesso em: dezembro de 2016.

CEPEA (São Paulo). PIB Agro-Brasil: Relatório PIB Agro-Brasil. 2017. Disponível em: <http://www.cepea.esalq.usp.br/upload/kceditor/files/Relatorio PIBAGRO Brasil_NOVEMBRO(1).pdf>. Acesso em: janeiro de 2017.

CEPEA-ESALQ (SÃo Paulo). Universidade de SÃo Paulo. METODOLOGIA. 2017. Disponível em: <https://www.cepea.esalq.usp.br/br/metodologia.aspx>. Acesso em: dezembro de 2016.

CEPEA-ESALQ (SÃo Paulo). Universidade de SÃo Paulo. Consulta ao Banco de Dados do

Site. Disponível em: 〈https://www.cepea.esalq.usp.br/br/consultas-ao-banco-de-dados-do-site.aspx>. Acesso em: dezembro de 2016.

CEPEA-ESALQ (SÃo Paulo). Universidade de SÃo Paulo. Metodologia para Cálculo dos Indicadores de Exportação do Agronegócio - CEPEA. 2017. Disponível em:

<https://www.cepea.esalq.usp.br/upload/kceditor/files/MetodologiaIndExportDetalhada.pdf>. Acesso em: dezembro 2016.

CHAMBERLAIN, S.; HOWE, J. S; POPPER, H. The Exchange Rate Exposure of U.S. and Japanese Banking Institutions. Journal of Banking and Finance, p. 871-892, 1997.

CHANG, Ya-Ting; GAU, Yin-Feng; HSU, Chih-Chiang. Liquidity Commonality in Foreign Exchange Markets During the Global Financial Crisis and the Sovereign Debt Crisis: Effects of Macroeconomic and Quantitative Easing Announcements. The North American Journal of Economics and Finance, v. 42, p. 172-192, 2017. https://doi.org/10.1016/j.najef.2017.06.004 
A relação entre o comportamento do indicador de liquidez corrente das empresas de capital aberto do agronegócio pela variação de índices econômicos no Brasil

CHIEN, C. N; CHENG, F. L. Dynamic relationship between stock prices and exchange rates for G-7 countries. The Quarterly Review of Economics and Finance, n. 41, p. 477-490, 2001.

https://doi.org/10.1016/S1062-9769(01)00085-0

CHOWDHURY, Anup; UDDIN, Moshfique; ANDERSON, Keith. Liquidity and Macroeconomic Management in Emerging Markets. Emerging Markets Review, 2017.

https://doi.org/10.1016/j.ememar.2017.10.001

COELHO, Lucia Borges. Efeitos de variáveis macroeconômicas no nível de liquidez de empresas brasileiras. Tese de Doutorado. Disponível em:

<http://bibliotecadigital.fgv.br/dspace/bitstream/handle/10438/13877/Dissertação\%20Lucia\%20Borges\% 20Coelho.pdf?sequence=3\&isAllowed=y $>$. Acesso em: janeiro de 2017 .

CNA - CONFEDERAÇÃO DA AGRICULTURA E PECUÁRIA DO BRASIL (Brasília). Panorama do Agro. 2019. Disponível em: https://www.cnabrasil.org.br/cna/panorama-do-agro. Acesso em: 20 abr. 2020.

COSTA, Tatiane Bento da et al. Real earning management no Brasil em duas condições de avaliação. 2017. http://doi.org/10.14393/ufu.di.2017.279

COTTRELL, Allin et al. Gretl User's Guide Gnu Regression, Econometrics and Time-series

Library. 2011. Disponível em: <http://gretl.sourceforge.net/pt.html>. Acesso em: junho de 2017.

CUPERTINO, C. M. Earnings management: estudo de caso do Banco Nacional. Revista Contabilidade \& Finanças, v. 17, n. 41, p. 110-120, 2006.

DIEESE; Nota técnica - O câmbio e suas influências na economia. São Paulo, 2006.

Disponível em: <https://www.dieese.org.br/notatecnica/2006/notatec24cambio.pdf>. Acesso em: dezembro de 2016.

FARINA, Elizabeth QM; ZYLBERSZTAJN, Dedo. Relações tecnológicas e organização dos mercados do sistema agroindustrial de alimentos. Cadernos de Ciência \& Tecnologia, v. 8, n. 1/3, p. 9-27, 1991.

FAVERO, L. P. et al. Análise de dados: modelagem multivariada para tomada de decisão. São Paulo: Campus, 2009.

FURTADO, Celso. Formação econômica do Brasil. Formação econômica do Brasil, 1959.

GUJARATI, D. N.; PORTER, D. C. Econometria básica. Tradução Denise Durante,

Mônica Rosemberg, Maria Lúcia G. L. Rosa. Porto Alegre, AMGH, 5. ed, 2011.

HALL, Rosemar José; BECK, Franciele; TOLEDO FILHO, Jorge Ribeiro. Análise do impacto da crise subprime nas empresas do agronegócio brasileiro listadas na BM\&FBovespa. Custos e @ gronegócio on line, v. 89, p. 900, 2012.

HORRIGAN, James O. A short history of financial ratio analysis. The Accounting Review, v. 43, n. 2, p. 284-294, 1968.

IBGE - Instituto Brasileiro De Geografia; ESTATÍSTICA. DEPARTAMENTO DE INDICES DE PREÇOS. Sistema nacional de índices de preços ao consumidor: índice nacional de preços ao consumidor: índice nacional de preços ao consumidor amplo, 1979-2019. IBGE, 2019. Disponível em:<https://www.ibge.gov.br/estatisticas/economicas/precos-e-custos/9256-indice-nacional-de-precosao-consumidor-amplo.html?=\&t=o-que-e>. Acesso em: 20 abr. 2020.

IUDICIBUS, Sergio de. Análise de balanços. Atlas, 2009. 
JOHNSON, R. A.; WICHERN, D. W. Applied multivariate statistical analysis. 6. Edition. New Jersey: Prentice Hall, 2007. 794p.

JUNIOR, José Braz Hercos. Análise de demonstrações contábeis e fatores macroeconômicos-doi: 10.4025/enfoque. v28i2. 9799. Enfoque: Reflexão Contábil, v. 28, n. 2, p. 09-26, 2009

KEYNES, John Maynard. A teoria geral do emprego, do juro e da moeda. São Paulo: Atlas, 1982.

KHAN, Muhammad Saifuddin; SCHEULE, Harald; WU, Eliza. Funding liquidity and bank risk taking. Journal of Banking \& Finance, v. 82, p. 203-216, 2017.

https://doi.org/10.1016/j.jbankfin.2016.09.005

KING, R. P.; BOEHLJE, M.; COOK, M. L.; SONKA, S. T. Agribusiness economics and management. American Journal of Agricultural Economics, v. 92, n. 2, p. 554-570, 2010.

https://doi.org/10.1093/ajae/aaq009

MINISTÉRIO DA AGRICULTURA, PECUÁRIA E ABASTECIMENTO (MAPA). AGROSTAT Estatisticas de Comércio Exterior do Agronegócio Brasileiro. 2019. Disponível em:

<http://sistemasweb.agricultura.gov.br/pages/AGROSTAT.html>Acesso em: abril de 2020.

MARION, José Carlos. Análise das demonstrações contábeis: Contabilidade Empresarial. São Paulo: Atlas, 2009.

MARTINS, Eliseu; MIRANDA, Gilberto José; DINIZ, Josedilton Alves. Análise didática das demonstrações contábeis. São Paulo: Atlas, 2014.

MARTINS, G. D. A.; THEÓPHILO, Carlos Renato. Metodologia da investigação cientifica. São Paulo: Atlas, 2009.

MISHRA, Ankita; BURNS, Kelly. The effect of liquidity shocks on the bank lending channel: Evidence from India. International Review of Economics \& Finance, v. 52, p. 55-76, 2017.

https://doi.org/10.1016/j.iref.2017.09.011

MUKHERJEE, Tarun K.; NAKA, Atsuyuki. Dynamic relations between macroeconomic variables and the Japanese stock market: an application of a vector error correction model. Journal of Financial Research, v. 18, n. 2, p. 223-237, 1995. Doi: 10.1111/j.1475-6803.1995.tb00563.x

NAKABASHI, Luciano. Efeitos do câmbio e juros sobre as exportações da indústria brasileira. 2008. Tese (Doutorado). Universidade Federal do Paraná.

NUNES, Sidemar Presotto. O desenvolvimento da agricultura brasileira e mundial e a idéia de Desenvolvimento Rural. Boletim eletrônico, DESER-Departamento de Estudos Socioeconômicos Rurais, p. 1-15, 2007. Disponível em:

<http://www.deser.org.br/documentos/doc/DesenvolvimentoRural.pdf >. Acesso em: dezembro de 2016.

OLIVEIRA, Jailson da Conceição Teixeira de; FRASCAROLI, Bruno Ferreira. Impacto dos fatores macroeconômicos na emissão de ações na bolsa de valores. Revista de Gestão, Finanças e

Contabilidade, v. 4, n. 1, p. 30, 2014.http://dx.doi.org/10.18028/rgfc.v4i1.484

OSAKI, Mauro. Ainda Somos Competitivos em Relação aos Nossos Concorrentes? 2017. Disponível em: <https://www.cepea.esalq.usp.br/br/opiniao-cepea/ainda-somos-competitivos-em-relacao-aos-nossosconcorrentes.aspx>. Acesso em: 20 dez. 2017.

PANDINI, Jardel; STÜPP, Diego Rafael; FABRE, Valkyrie Vieira. Análise do Impacto das Variáveis 
A relação entre o comportamento do indicador de liquidez corrente das empresas de capital aberto do agronegócio pela variação de índices econômicos no Brasil

Macroeconômicas no Desempenho Econômico-Financeiro das Empresas dos Setores de Consumo Cíclico e Não Cíclico da BM\&FBovespa. Revista Catarinense da Ciência Contábil, v. 17, n. 51, p.7-22. http://dx.doi.org/10.16930/2237-7662/rccc.v17n51.2606

KRUGMAN, Paul R.; OBSTFELD, Maurice. Economía internacional: Teoría y política. Pearson, 2012.

PEACE CORPUS. Small and Medium Scale Agribusiness Assessment. Peace Corpus Information Collection \& Exchange Reprint, Washington DC. May 1983. Disponível em: Acesso em 02/03/2013. Disponível em: 〈https://files.eric.ed.gov/fulltext/ED307463.pdf〉. Acesso em: dezembro de 2017.

PINHO, D. B.; VASCONCELLOS, M.A.S. Manual de Economia - Equipe de professores da USP: São Paulo. - 2. ed., 4a. tiragem - São Paulo: Saraiva, 1996.

PREVE, Lorenzo; SARRIA-ALLENDE, Virginia. Working capital management. Oxford University Press, 2010.

PNAD, IBGE. Pesquisa Nacional por amostra de domicílios 2015. Instituto Brasileiro de Geografia e Estatística. Rio de Janeiro: IBGE, IBGE (Instituto Brasileiro de Geografia e Estatística), 2015. Disponível em: <https://biblioteca.ibge.gov.br/visualizacao/livros/liv98887.pdf>. Acesso em: abril de 2020.

RAJULTON, F. The Fundamentals of Longitudinal Research: An Overview. Canadian Studies in Population, v. 28, n. 2, p. 169-185. 2001.

RAUPP, F. M.; BEUREN, I. M. Metodologia da pesquisa aplicável às ciências sociais. In: BEUREN, I. M. (Org.). Como elaborar trabalhos monográficos em contabilidade: teoria e prática. São Paulo: Atlas, 2003.

SANTOS, F.M.; TEIXEIRA, A.; COIMBRA, P.C.; DALMÁCIO, F.Z. Impacto das flutuações econômicas no desempenho das empresas: estudo intra-setorial sob a perspectiva da teoria dos ciclos econômicos. In: Congresso ANPCONT (2008), Anais... Salvador, 2008.

SERIGATI, Felippe Cauê. A macroeconomia da agricultura. AgroANALYSIS, v. 33, n. 01, p. 15-16, 2013.

SHASHUA, L.; GOLDSCHMIDT, Y. An index for evaluating financial performance. The Journal of Finance, v. 29, n. 3, p. 797-814, 1974.

SILVA, Kelly Aparecida; BORGES, Sabrina Rafaela Pereira; MIRANDA, Gilberto José. Fora da caixinha: uma avaliação do ambiente externo na análise setorial. In Congresso UFU de Contabilidade, 2017. Anais..., 2017.

SINGH, Anamika; SHARMA, Anil Kumar. An empirical analysis of macroeconomic and bank-specific factors affecting liquidity of Indian banks. Future Business Journal, v. 2, n. 1, p. 40-53, 2016. https://doi.org/10.1016/j.fbj.2016.01.001

SOARES, Patrícia de Carvalho Diniz; FUNCHAL, Bruno. O Efeito Da Inflação Sobre A Estrutura De Capital Das Empresas Brasileiras: Uma Análise Setorial. In Congresso Brasileiro de Contabilidade, 18., 2008. Anais...,Gramado, 2008.

SOENEN, L. A.; AGGARWAL, R. Financial prices as determinants of changes in currency values. In: Annual Meetings of Eastern Finance Association, 25 ${ }^{\text {th }}$., Philadelphia. 1989. p. 2-2. Anais...n 1989 
SOENEN, Luc A.; HENNIGAR, Elizabeth S. An analysis of exchange-rates and stock-prices-the unitedstates experience between 1980 and 1986. Akron Business and Economic Review, v. 19, n. 4, p. 7-16, 1988. https://doi.org/10.1016/S1044-0283(98)90006-0

SOLNIK, Bruno. Using financial prices to test exchange rate models: A note. The Journal of Finance, v. 42, n. 1, p. 141-149, 1987.

SONAGLIO, Cláudia Maria; CAMPOS, Antonio Carvalho; BRAGA, Marcelo José. Effects of interest and exchange rate policies on Brazilian exports. Economia, v. 17, n. 1, p. 77-95, 2016.

https://doi.org/10.1016/j.econ.2016.01.002

SWITZER, Lorne N.; PICARD, Alan. Stock market liquidity and economic cycles: A non-linear approach. Economic Modelling, v. 57, p. 106-119, 2016.

TAKAMATSU, Renata Turola, LAMOUNIER, Wagner Moura. Impactos Da Política Cambial No Agronegócio Brasileiro: Uma análise das empresas de capital aberto por meio de seus indicadores financeiros; 2007. Disponível em: <http://www.sober.org.br/palestra/6/772.pdf $>$. Acesso em: dezembro de 2016.

TRENCA, Ioan; PETRIA, Nicolae; COROVEI, Emilia Anuta. Impact of Macroeconomic Variables upon the Banking System Liquidity. Procedia Economics and Finance, v. 32, p. 1170-1177, 2015. https://doi.org/10.1016/S2212-5671(15)01583-X

VASCONCELLOS, Marco Antonio Sandoval de. Economia: micro e macro. São Paulo: Atlas, v. 3, 2001.

VASCONCELLOS, Marco Antonio Sandoval de; ENRIQUEZ GARCIA, Manuel. Fundamentos de economia. 4. ed. São Paulo: Saraiva, 2012.

VERGARA, S. C. Projetos e relatórios de pesquisa em administração. $10^{\circ}$ ed. São Paulo: editora Atlas, 2009.

ZYLBERSZTAJN, D. (1995). Estruturas de governança e coordenação do agribusiness: uma aplicação da nova economia das instituições. Disponível em:

<http://www.fundacaofia.com.br/pensa/anexos/biblioteca/63200715534_.pdf >. Acesso em: dezembro de 2016.

WOOLDRIDGE, J. M.. Introdução à econometria: Uma abordagem moderna. Tradução: José Antônio Ferreira. Revisão Técnica: Galo Carlos Lopes Noriega. 4. Ed. São Paulo/SP: Cengage Learning, 2010. 